Research Article

\title{
Buckling Behavior and Effective Width Design Method for Thin Plates with Holes under Stress Gradient
}

\author{
Yanli Guo $\mathbb{D}^{1}$ and Xingyou Yao $\mathbb{D}^{2}$ \\ ${ }^{1}$ School of Civil Engineering and Architecture, Nanchang University, Nanchang, China \\ ${ }^{2}$ Jiangxi Province Key Laboratory of Hydraulic and Civil Engineering Infrastructure Security, Nanchang Institute of Technology, \\ Nanchang, China \\ Correspondence should be addressed to Yanli Guo; 2013994413@nit.edu.cn
}

Received 27 February 2021; Revised 21 May 2021; Accepted 12 July 2021; Published 21 July 2021

Academic Editor: Jose Renato de Sousa

Copyright (c) 2021 Yanli Guo and Xingyou Yao. This is an open access article distributed under the Creative Commons Attribution License, which permits unrestricted use, distribution, and reproduction in any medium, provided the original work is properly cited.

\begin{abstract}
This paper aims at investigating the elastic buckling behavior and the effective width method (EWM) to predict the ultimate strength of the simply supported rectangular plates under gradient stress (SSRPSG) with circular or rectangular holes. The analytical models of SSRPSG with circular or rectangular holes were established by using the finite-element (FE) software ABAQUS. The FE parametric study covered the aspect ratio, slenderness ratio, and stress gradients of plate and the dimension and spacing of holes. The FE analysis included eigenvalue buckling analysis and ultimate strength analysis. The eigenvalue results show that the buckling coefficient of the perforated plate gradually decreases, and subsequently, it gradually increases with the increase of the dimension of the hole. The buckling mode changes from the buckling including hole to the buckling of plate strip adjacent to hole at the section of the hole. The increasing stress gradient causes an increasing effect on buckling coefficient. The buckling coefficients are less affected by the aspect ratio and the slenderness ratio of the perforated plate and the spacing of hole when the hole spacing meets a certain limitation. The buckling coefficient equations of the SSRPSG with circular or rectangular holes were developed according to results obtained by FE analysis. Finally, the effective width design method was developed based on FE results and developed buckling coefficient equations. The comparisons on ultimate strength between FE results and the predicted results for SSRPSG with circular and rectangular holes and between the predicted results and test results for perforated columns and beams indicate that the proposed effective width design method is accurate, which can be used to predict the ultimate strength of SSRPSG with circular or rectangular holes.
\end{abstract}

\section{Introduction}

Cold-formed thin-walled steel plain and lipped channels as structural members have been widely used in various structural fields due to their great strength to weight ratio and ease of construction. The channel sections used in the walls, floor, and ceilings of buildings often include holes in the web for installation of plumbing, electrical, and heating conduits. However, the behavior of this kind of section becomes more and more complex because the opening will lead to redistribution of stresses, change of buckling modes, and decrease of load capacity and stiffness.

Stub column tests conducted by Ortiz-Colberg [1] demonstrated that the ultimate load capacities decrease with the increase of the ratio of circular hole diameter to web height. Similar conclusions have also been reported when the effects of circular, rectangular, and slotted web openings on the ultimate strength of stub columns were assessed $[2,3]$. The compression tests of 24 short and intermediate length cold-formed steel columns with and without slotted web holes were carried out by Moen and Schafer [4]. The research results indicated that the presence of slotted holes causes only a slight decrease in the ultimate strength of the test columns, although the postpeak response and column ductility are influenced. An experimental study performed by He and Zhao [5] indicated that the stress of plate adjacent to circle hole was greater than at other parts, and the plate adjacent to circle hole also yielded earlier than other parts. 
For lipped channel columns with web stiffener, the numerical and experimental studies were performed to evaluate the effects of holes on the ultimate strength by Yao et al. [6]. The results demonstrated that the web holes led the change of bucking modes and decreased the load-carrying capacity. The direct strength method for predicting the ultimate strength of perforated columns was proposed by Moen and Schafer based on theoretical and experimental studies [7]. Meanwhile, the experiments and direct strength methods for perforated plain channel section beam [8] and lipped channel section beams $[9,10]$ were also reported. The results showed that the web holes also lead to the decrease of the bending capacity. It is necessary to note that the elastic buckling stress or buckling coefficients of perforated plates and members is an essential issue for predicting the ultimate strength of perforated members from the outcome of these research studies.

The elastic buckling stress or buckling coefficients of perforated plates and members have been investigated by some researchers. The simplified methods for approximating the global, distortional, and local critical elastic buckling loads of cold-formed steel columns and beams with holes were developed based on theoretical and FE analysis by Moen and Schafer [11]. Yao developed the calculated method for elastic distortional buckling stress of perforated members under axial compression by using FE analysis [12]. The thin shell finite element was used to study the elastic buckling of simply supported rectangular plate with multiple holes with different sizes and spacing by some researchers [13-16]. The results indicated that the presence of holes can either decrease or increase the critical elastic buckling stress and change the quantity and length of buckled half wave. The buckling behavior of plates with rectangular holes studied by Brown, Yettram, and Burnett indicated that the elastic buckling capacity would increase under uniaxial compression or biaxial compression when hole size is more than a limit value [17]. El-Sawy and Nazmy [13, 18] studied the effect of the aspect ratio and hole location on elastic buckling capacity of perforated plate and recommended to avoid punching hole near the plate edge. The closed-form expressions for approximating the effect of single or multiple holes on the critical elastic buckling stress of plates in bending or compression were developed by Moen and Schafer based on FE analysis [19]. For a perforated plate under axial compression [20] and bending [21], the predicted expressions for buckling coefficients were proposed by Liu and Su according to the FE analysis, respectively. However, the developed expressions for buckling coefficients could not calculate the buckling coefficient of perforated plate under stress gradient. The research conducted by Kawai and Ohtsubo showed that holes can reduce bending stiffness and concentrate axial load for the plate strips adjacent to the hole [22]. This kind of phenomenon led to a useful approximate method to calculate the elastic buckling stress for plates with holes, which assumes the plate strips adjacent to the hole act as a plate simply supported on 3 sides and free on the fourth side adjacent to the hole. The design formula for calculating the ultimate strength of plates with circular or rectangular holes under uniaxial compression or biaxial compression with different boundary conditions were proposed by Shanmugam, Thevendran, and Tan [23] according to finite-element analysis. In those literature studies [1-14, 17-23], the research studies of design equations of the elastic critical buckling stress, buckling coefficients, and effective width only considered about the thin plate with holes under uniform compression or bending. Nevertheless, limited works were reported on thin plates with holes under stress gradient $[15,16]$.

Furthermore, in terms of the effective width design method for perforated plates and members, the American Iron and Steel Institute (AISI) [24] and the Australian and New Zealand Standards (AS/NZS) [25] do not provide sufficient design rules because the reduced effective width design method is only suitable to perforated plates and members with relatively small holes in these codes. Meanwhile, there is no design provision about the perforated plates and members in the Chinese code [26].

This paper presents the results of an extensive parametric study to evaluate the buckling coefficients, buckling modes, and ultimate strength of the SSRPSG with circular or rectangular holes which are centered at the plate by using the FEM. The effects of the slenderness ratio and aspect ratio of plate and size and spacing of hole on the buckling coefficients and buckling modes were investigated. Design equations for determining the buckling coefficients and effective width of SSRPGS with circular or rectangular holes were developed. The efficiency and accuracy of buckling coefficients and effective width equations in predicting the ultimate strength of the thin plate and cold-formed thinwalled steel members with holes were verified through a comparison on the load-carrying capacity for the coldformed thin-walled steel members with holes in some tests.

\section{Development and Validation of Finite- Element Models}

2.1. Finite-Element Analysis Model and Analysis Procedure. The finite-element software ABAQUS [27] was used to develop the analysis model for the SSRPSG. The analysis model is subjected to linearly varying loading. Notation for the rectangular plate containing holes is provided in Figure 1 . The length, width, and thickness of thin plate are $a, b$, and $t$, respectively. The diameter of circular hole is $d$. The rectangular hole has the length $L_{h}$ and the height $H_{h}$. The center-to-center hole spacing is $S$. The number of holes is $n$. The distance between the plate outer edge and the center of the hole is $X_{\mathrm{e}}$. The ratio of edge distance to width of plate $\left(X_{\mathrm{e}} /\right.$ $b$ ) is more than 2 in the FE analysis because the edge distance has no effect on the buckling stress and buckling coefficient when $X_{\mathrm{e}} / b$ meets this condition according to the studied results in references $[20,21]$.

As shown in Figure 2, the perforated plates are modeled with simply supported boundary conditions on 4 sides. All four edges are free to wave and have no lateral edge displacement perpendicular to the plate plane. The plate was discretized into a mesh consisting of quadrilateral shell elements. The typical finite-element mesh used in the present analysis is shown in Figure 2 for the plate with circular and 


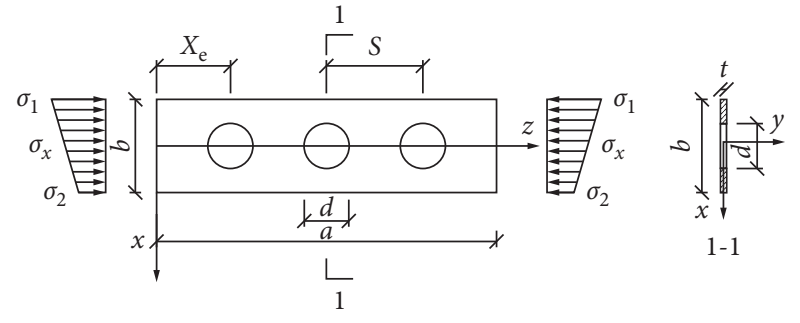

(a)

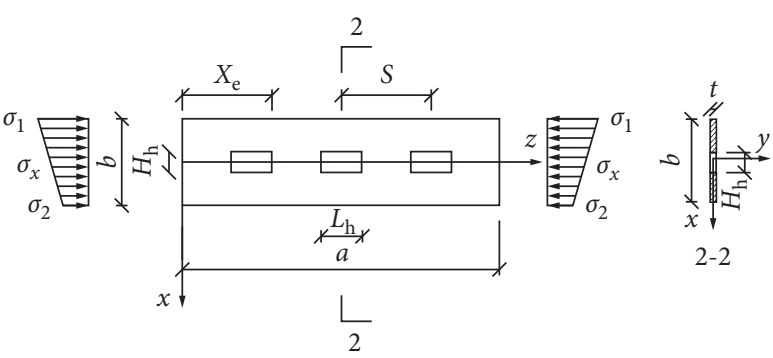

(b)

Figure 1: Perforated thin plate model. (a) Thin plate with circular hole. (b) Thin plate with rectangular hole.

rectangular hole. A denser or graded mesh was adopted around the holes as shown in Figures 2(e) and 2(f). A linearly varying force in the longitudinal direction expressed in formula (1) is applied to two opposite edges $(z=0$ and $z=a)$ as consistent nodal loads in ABAQUS:

$$
\sigma_{x}=\sigma_{1}\left(1-\frac{(1-\psi)}{b}\left(x+\frac{b}{2}\right)\right),
$$

where $\psi=\sigma_{2} / \sigma_{1}$ is the stress gradient coefficient, $\sigma_{1}$ is the maximum edge compression stress, $\sigma_{2}$ is the minimum edge stress at another edge, and positive value and negative value represent compression and tension, respectively.

Different loading cases, which mean different stress gradients, may be obtained by changing $\psi$ in equation (1). For instance, if $\sigma_{2}$ is equal to $\sigma_{1}$, a uniformly distributed compression is applied. By taking $\sigma_{2}=-\sigma_{1}$, pure in-plane bending is obtained.

A perfectly elastic-plastic stress-strain curve (see Figure 3) obeying the Mises yield criterion was adopted to model the perforated plates in the parametric study. The material properties for Young's modulus $E=206000 \mathrm{MPa}$, yield stress $f_{\mathrm{y}}=550 \mathrm{MPa}$, and Poisson coefficient $v=0.3$ were selected because the yield strength has no effect on the elastic buckling behavior and buckling coefficient. The residual stresses of the sections were not included in the model. All finite-element models utilized the S9R5 reduced integration nine-node thin shell element. Linear and nonlinear analyses were performed. The linear elastic buckling analysis (or eigenvalue analysis) was performed to determine the critical elastic buckling stress and buckling mode. The nonlinear analysis was carried out to obtain the ultimate strength. The first buckling mode deformation obtained in linear buckling analysis was used as the initial geometric imperfection. Since a peak load is anticipated in nonlinear analysis, the arclength control method was used to trace the load-displacement curve. The loading stopped when the applied load reached the 85 percent of peak load of the perforated plate.

2.2. Verification of Finite-Element Model. In order to verify the accuracy of the presented FE model, the results obtained by ABAQUS are compared to those results obtained by using an exact solution procedure based on the infinite power series [28]. The buckling coefficients $k_{c r}^{*}$ for the SSRPSG without holes obtained by ABAQUS and the corresponding values $k_{0}^{*}$ obtained from Kang and Leissa [28] are listed in Table 1 , in which the buckling coefficient is calculated by using the following formula:

$$
k=\sigma c r \frac{12\left(1-v^{2}\right)}{\pi^{2} E}\left(\frac{b}{t}\right)^{2} .
$$

As shown in Table 1, a perfect consistency is obtained between FE analysis and the results in terms of buckling coefficients, which indicates that the FE model presented in this paper is accurate and reliable. It needs to be noted that the buckling coefficients of SSRPSG keep a constant magnitude when the length of the plate increases relative to the width of plate, so the FE analysis in this paper will ignore the effect of the ratio of length-to-width of the plate.

\section{Elastic Buckling of Rectangular Thin Plate with Circular Holes}

\subsection{Thin Plate with a Single Hole}

3.1.1. Effects of b/t Ratio. The buckling coefficients for the SSRPSG with a circular hole ( $\psi$ ranging from 1 to -1 ), different slenderness ratios $(b / t=50,100$, and 150$)$, the aspect ratio $a / b=8$, and the hole size $(d / b=0.5)$ were analyzed by using FE method. The results are listed in Table 2, where $k_{50}, k_{100}$, and $k_{150}$ are the buckling coefficients for SSRPSG with a circular hole at the slenderness ratio equaling to 50,100 , and 150 , respectively.

It can be observed from Table 2 that the buckling coefficients for perforated plates with different slenderness ratios $b / t$ are almost the same. Hence, the slenderness ratio $(b / t)$ has no effect on the buckling coefficients of the SSRPSG with a circular hole.

3.1.2. Effects of $d / b$ Ratio. Figures 4 and 5 present the variation of the deformations of the first buckling mode and buckling coefficients for SSRPSG with a circular hole, covering a slenderness ratio $b / t$ of 100 , an aspect ratio $a / b$ of 8 , different stress gradients ( $\psi$ ranging from 1 to -1 ), and different hole sizes $(d / b$ ranging from 0.1 to 0.8 ). Figure 2 only shows the variation of buckling modes for a perforated plate with a stress gradient coefficient $\psi=-1 . k_{\mathrm{a}}$ and $k_{\mathrm{c}}$ are buckling coefficients for perforated and nonperforated plates in Figure 5. 


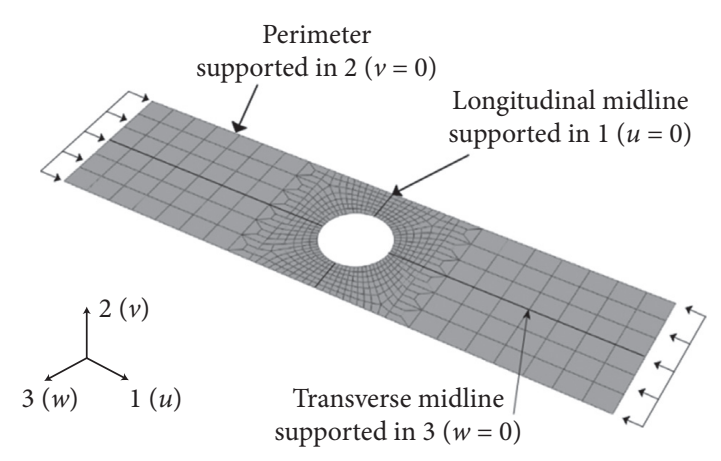

(a)

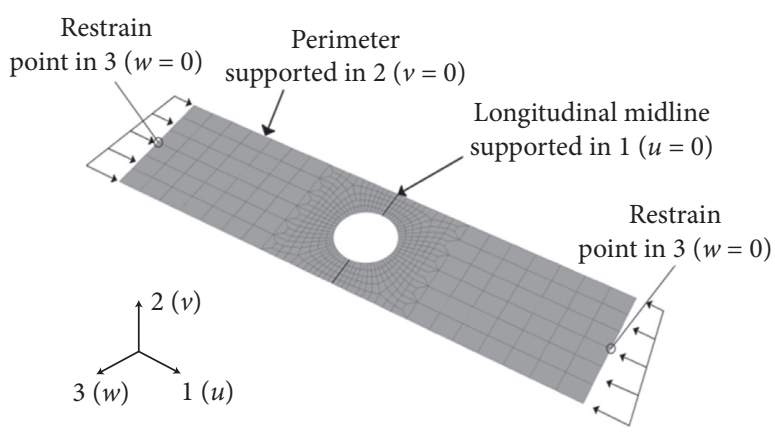

(c)

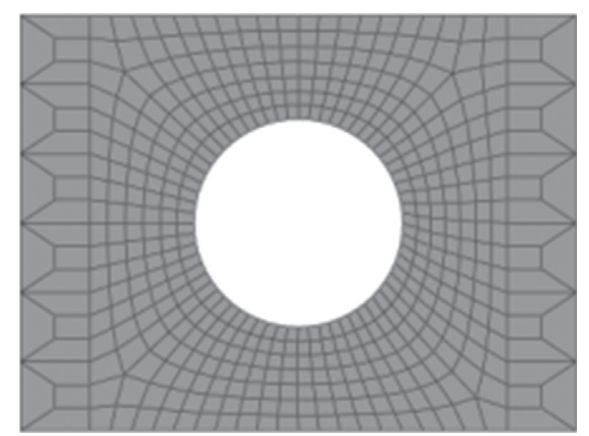

(e)

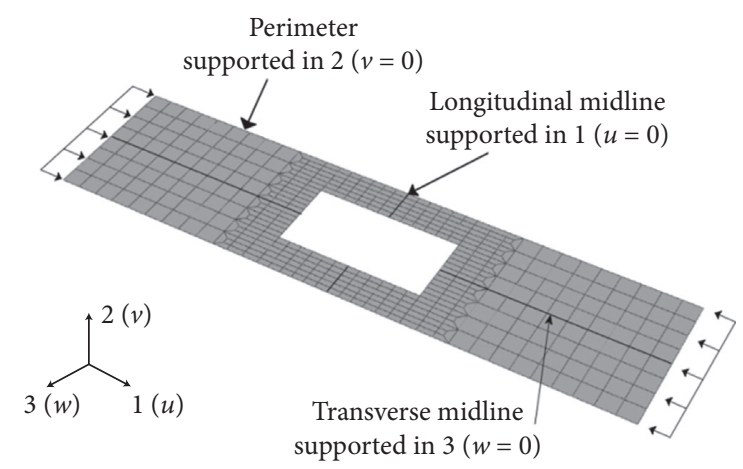

(b)

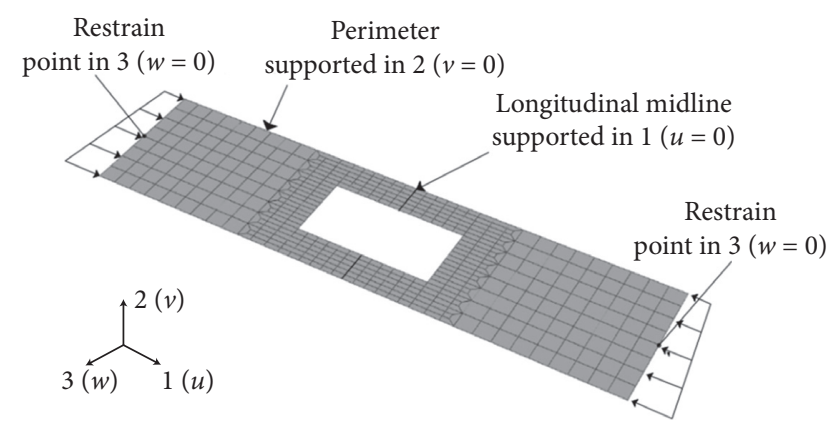

(d)

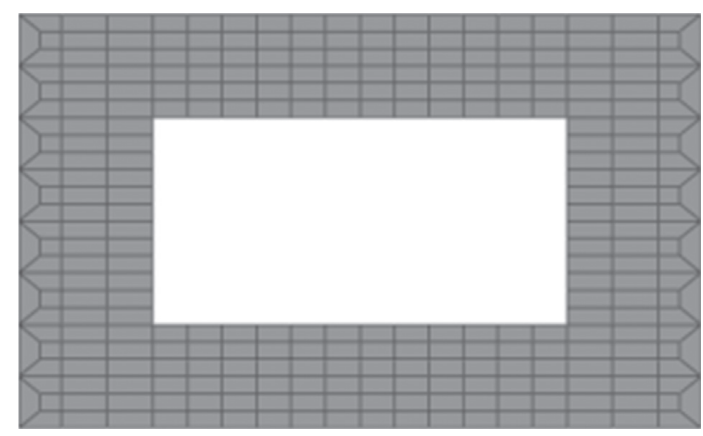

(f)

FIGURE 2: ABAQUS boundary and mesh for the simply supported plate with hole. (a) Thin plate with circular hole under axial compression. (b) Thin plate with rectangular hole under axial compression. (c) Thin plate with circular hole under eccentrically axial compression or bending. (d) Thin plate with rectangular hole under eccentrically axial compression. (e) Mesh around the circular hole. (f) Mesh around the rectangular hole.

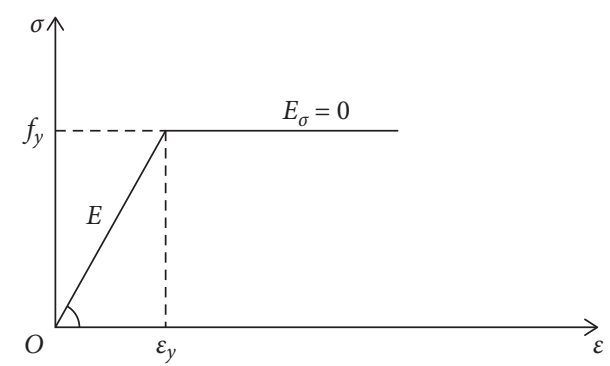

FIGURE 3: The perfectly elastic-plastic stress-strain curve.

As demonstrated in Figure 4, for plates with smaller holes $(d / b=0.1,0.2)$ the local buckling including the hole is prominent at the section of hole. The buckling of the plate strip adjacent to the hole occurs with the increase of the dimension of the hole $(d /$ $b=0.3,0.4,0.5,0.6$, and 0.7$)$. However, buckling occurs away from the hole when the plate has a larger hole $(d / b=0.8)$.

As shown in Figure 5, the buckling coefficients of the SSRPSG with a circular hole predicted with equation (2) decrease firstly. For instance, the buckling coefficient is decreased maximally by $13.5 \%$ for bending plate. Then, buckling coefficients increase with the increase of dimensions of holes. We need to note that the increase in buckling coefficients for large holes does not indicate an increase in ultimate strength because the strength of the plate will be limited by the strength of the effective net cross section.

\subsection{Thin Plate with Multiple Holes}

3.2.1. Effects of $S / D$ Ratio. Figure 6 shows the variation of the buckling coefficient for SSRPGS with multiple circular holes, 
TABLE 1: Comparison on the buckling coefficients between finite-element results and exact results.

\begin{tabular}{|c|c|c|c|c|c|c|c|c|c|}
\hline \multirow{2}{*}{$\psi$} & \multicolumn{3}{|c|}{$a / b=1$} & \multicolumn{3}{|c|}{$a / b=2$} & \multicolumn{3}{|c|}{$a / b=3$} \\
\hline & $k_{c r}^{*}$ & $k_{0}^{*}$ & $\left(k_{c r}^{*}-k_{0}^{*}\right) / k_{0}^{*}$ & $k_{c r}^{*}$ & $k_{0}^{*}$ & $\left(k_{c r}^{*}-k_{0}^{*}\right) / k_{0}^{*}$ & $k_{c r}^{*}$ & $k_{0}^{*}$ & $\left(k_{c r}^{*}-k_{0}^{*}\right) / k_{0}^{*}$ \\
\hline-1 & 24.58 & 25.66 & $4.394 \%$ & 23.41 & 23.91 & $2.136 \%$ & 23.75 & 24.11 & $1.516 \%$ \\
\hline-0.5 & 12.89 & 13.39 & $3.879 \%$ & 13.18 & 13.45 & $2.049 \%$ & 13.27 & 13.42 & $1.130 \%$ \\
\hline 0 & 7.40 & 7.82 & $5.676 \%$ & 7.59 & 7.83 & $3.162 \%$ & 7.65 & 7.79 & $1.830 \%$ \\
\hline 0.5 & 5.04 & 5.32 & $5.556 \%$ & 5.17 & 5.36 & $3.675 \%$ & 5.21 & 5.31 & $1.919 \%$ \\
\hline 1 & 4.00 & 4.00 & 0 & 4.00 & 4.00 & 0 & 4.00 & 4.00 & 0 \\
\hline
\end{tabular}

TABLE 2: Buckling coefficients of plate with circle hole for different slenderness ratios.

\begin{tabular}{lccccc}
\hline$\psi$ & $k_{50}$ & $k_{100}$ & $k_{150}$ & $\left(k_{100}-k_{50}\right) / k_{50}$ & $\left(k_{150}-k_{50}\right) / k_{50}$ \\
\hline-1 & 18.37 & 18.51 & 18.59 & $0.762 \%$ & $1.198 \%$ \\
-0.5 & 11.63 & 11.72 & 11.75 & $0.774 \%$ & $1.032 \%$ \\
0 & 7.84 & 7.88 & 7.89 & $0.510 \%$ & $0.638 \%$ \\
0.5 & 5.47 & 5.49 & 5.50 & $0.366 \%$ & $0.548 \%$ \\
1 & 3.82 & 3.83 & 3.84 & $0.262 \%$ & $0.524 \%$ \\
\hline
\end{tabular}

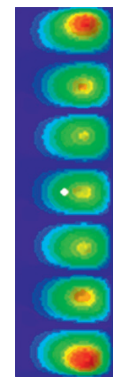

(a)

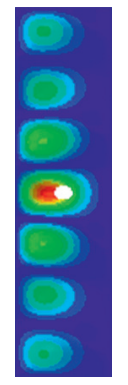

(b)

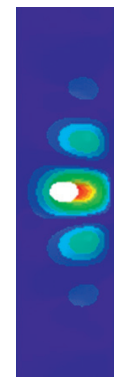

(c)

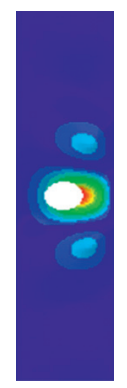

(d)

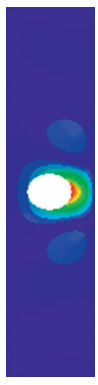

(e)

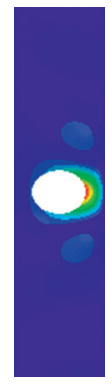

(f)

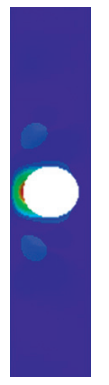

(g)

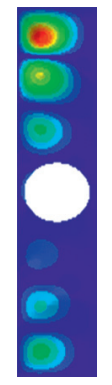

(h)

Figure 4: The deformations of first buckling mode for plates with different hole sizes $(\psi=-1)$. (a) $d / b=0.1$. (b) $d / b=0.2$. (c) $d / b=0.3$. (d) $d /$ $b=0.4$. (e) $d / b=0.5$. (f) $d / b=0.6$. (g) $d / b=0.7$. (h) $d / b=0.8$.

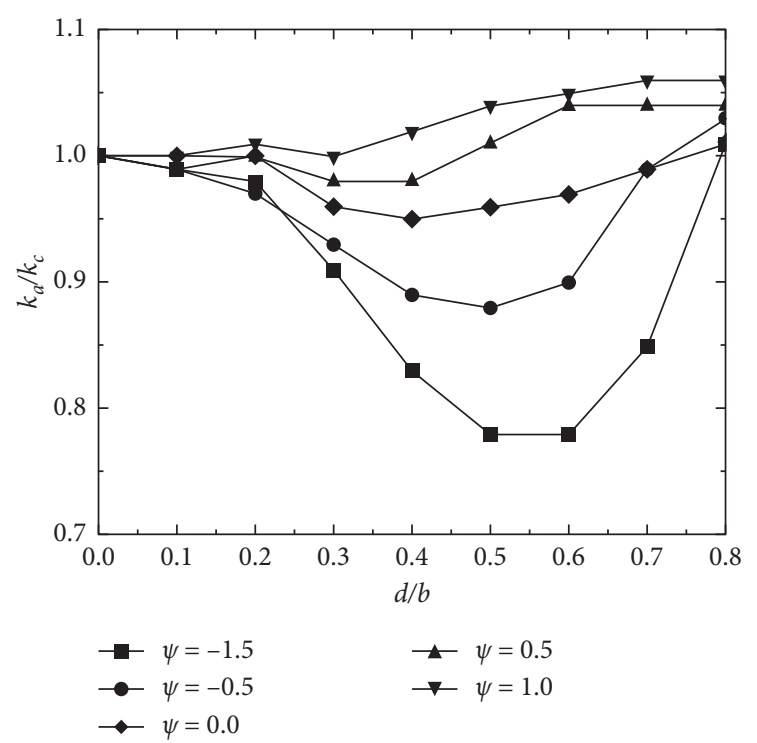

FIgURE 5: Buckling coefficients for plate with a circle hole and different hole sizes. covering a slenderness ratio $b / t$ of 100 , an aspect ratio $a / b$ of 8 , different stress gradients ( $\psi$ ranging from 1 to -1 ), different hole sizes $(d / b$ ranging from 0.1 to 0.8$)$, and different hole spacings ( $S / d$ ranging from 2 to 10 ). The buckling coefficients converge to a constant magnitude as the increase of the ratio of the length of plate to the diameter of the hole. When $S / d$ exceeds 4 , the errors in the evaluation of buckling coefficients are less than $3 \%$ which demonstrates that the influence of the holes spacing is not important. So, the buckling coefficients can be predicted by considering $S / d=4$ when $S / d$ exceeds 4 for the SSRPSG with multiple circular holes.

3.2.2. Effect of Number of Holes. The effect of the number of holes can be studied when the hole spacing is constant from Table 3. The SSRPSG with multiple circular holes consider the slenderness ratio $(b / t=100)$, only one hole size $(d / b=0.5)$, hole spacing $(S / d=4)$, different lengths of plate, and different stress gradients ( $\psi$ ranging from 1 to -1 ). Plates with 3,5 , and 7 holes were investigated, where $k_{3}, k_{5}$, and $k_{7}$ represent the buckling coefficients of plates with 3,5 , and 7 holes, respectively. It can be observed that the number of holes has no effect on the 

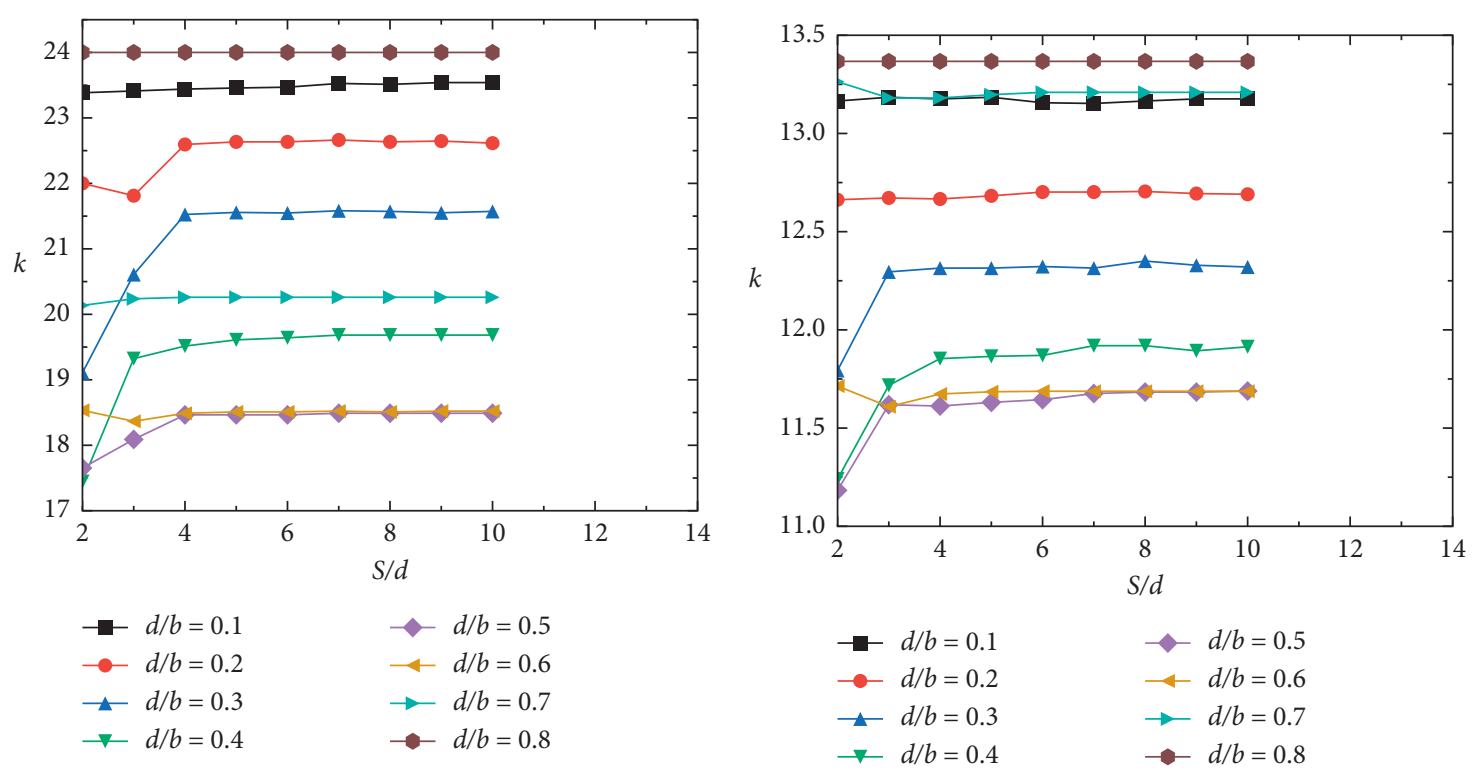

(a)

(b)
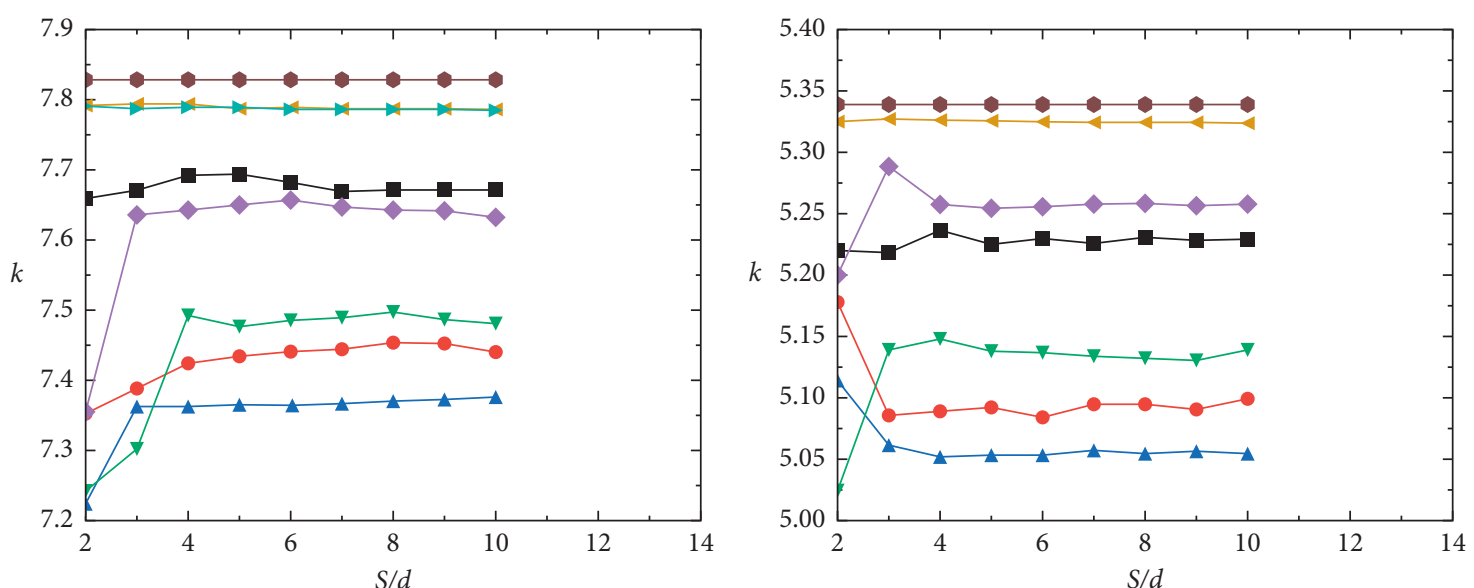

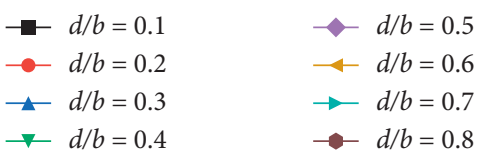

(c)
$-d / b=0.1$
$\longrightarrow d / b=0.2$
$\leftarrow d / b=0.3$
$\rightarrow d / b=0.4$
$-d / b=0.5$
$\leftarrow d / b=0.6$
$\rightarrow d / b=0.7$
$\longrightarrow d / b=0.8$

(d)

Figure 6: Continued. 


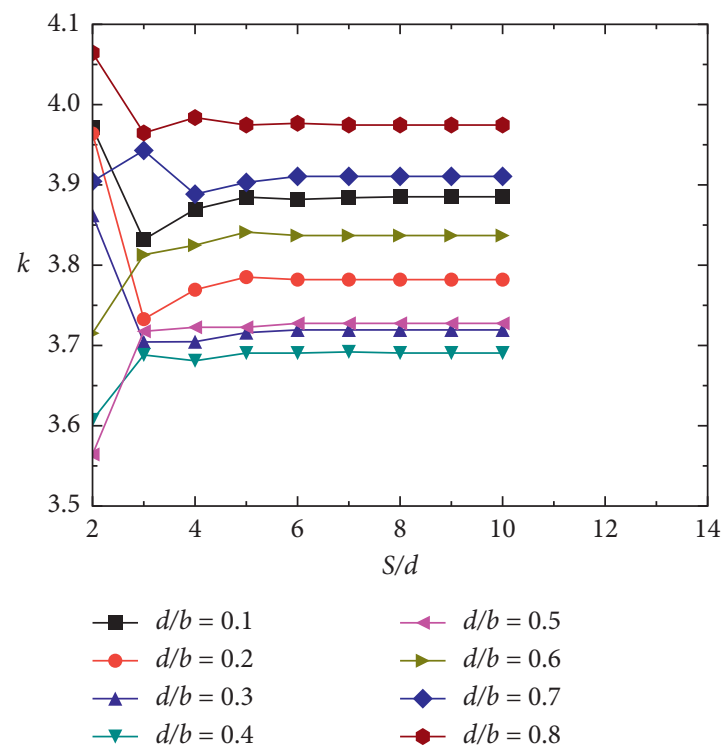

(e)

FIgURE 6: Buckling coefficients for plate with different hole spacing. (a) $\psi=-1$. (b) $\psi=-0.5$. (c) $\psi=0$. (d) $\psi=0.5$. (e) $\psi=1$.

TABLE 3: Buckling coefficients for plate with different hole numbers.

\begin{tabular}{lccc}
\hline$\psi$ & $k_{3}$ & $k_{5}$ & $k_{7}$ \\
\hline-1 & 20.36 & 20.36 & 20.36 \\
-0.5 & 13.21 & 13.18 & 13.17 \\
0 & 7.67 & 7.69 & 7.71 \\
0.5 & 5.23 & 5.24 & 5.24 \\
1 & 3.85 & 3.84 & 3.81 \\
\hline
\end{tabular}

buckling coefficient for the SSRPSG with multiple circular holes if the hole spacing is more than $4 d$.

3.2.3. Comparison on Buckling Coefficient for Plate with Single Hole and Multiple Holes. The comparison on the buckling coefficient between the plate with a circular hole and the plate with three circular holes is given in Table 4, where $k_{\mathrm{mh}}$ and $k_{\mathrm{oh}}$ are the buckling coefficients of plate with three circular holes and plate with one circular hole. The current comparison covers the perforated plate with different hole spacings $(S / d=4,6,8$, and 10$)$ and different stress gradients ( $\psi$ ranging from 1 to -1 ). The hole size $d / b=0.5$. It can be observed from Table 4 that the buckling coefficients of the plate with three circular holes and the plate with one circular hole are almost the same when hole spacing $S / d$ is more than 4 . The comparison results indicate that the buckling coefficient of plate with multiple holes can be predicted as the plate from the model with one circular hole when hole spacing $S / d$ is more than 4 .
3.3. Proposed Buckling Coefficient Equations. The buckling mode for the SSRPSG with circular holes can change from the buckling including the hole (see Figure 4(a)) to the buckling of plate strip adjacent to hole (see Figure $4(\mathrm{e})$ ) at the section of hole. The relationship between critical hole size of changing of buckling modes and the stress gradient can be obtained based on finite-element analysis and plotted in Figure 7. The critical hole size of change of buckling modes can be expressed as equation (3) which is obtained according to fit the curve in Figure 7:

$$
d / b=0.06 \psi^{2}-0.14 \psi+0.40
$$

So, the buckling coefficient of the SSRPSG with circular holes should be predicted considering two cases which correspond to two buckling modes: (1) the buckling including the hole when the hole size is less than equation (3) and the plate should be considered as a stiffened plate with hole; (2) buckling of the plate strip adjacent to hole, when the hole size is more than equation (3) and the plate strip should be considered as a unstiffened plate.

For the first buckling mode, the buckling coefficient of the stiffened plate with hole can be obtained from FE analysis plotted in Figure 8.

The $d / b$ and $\psi$ are the primary parameters affecting the buckling coefficient as shown in Figure 8. Therefore, the buckling coefficients of the stiffened plate with circular hole under stress gradient can be calculated using equation (4) which is obtained according to fit the curves in Figure 8:

$$
k= \begin{cases}\left(7.8-6.29 \psi+9.78 \psi^{2}\right) \times\left[-0.72(d / b)^{2}+0.23 \psi(d / b)+0.07(d / b)+1\right], & -1 \leq \psi \leq 0 \\ \left(7.8-8.15 \psi+4.35 \psi^{2}\right) \times\left[1.06(d / b)^{2}-0.25 \psi(d / b)-0.21(d / b)+1\right], & 0<\psi \leq 1\end{cases}
$$


TABLE 4: Comparison on buckling coefficients for plate with single hole and multiple holes.

\begin{tabular}{|c|c|c|c|c|c|c|c|c|c|c|c|c|}
\hline \multirow{2}{*}{$\psi$} & \multicolumn{3}{|c|}{$S / d=4$} & \multicolumn{3}{|c|}{$S / d=6$} & \multicolumn{3}{|c|}{$S / d=8$} & \multicolumn{3}{|c|}{$S / d=10$} \\
\hline & $k_{\mathrm{mh}}$ & $k_{\mathrm{oh}}$ & $\left(k_{\mathrm{mh}}-k_{\mathrm{oh}}\right) / k_{\mathrm{oh}}$ & $k_{\mathrm{mh}}$ & $k_{\mathrm{oh}}$ & $\left(k_{\mathrm{mh}}-k_{\mathrm{oh}}\right) / k_{\mathrm{oh}}$ & $k_{\mathrm{mh}}$ & $k_{\mathrm{oh}}$ & $\left(k_{\mathrm{mh}}-k_{\mathrm{oh}}\right) / k_{\mathrm{oh}}$ & $k_{\mathrm{mh}}$ & $k_{\mathrm{oh}}$ & $\left(k_{\mathrm{mh}}-k_{\mathrm{oh}}\right) / k_{\mathrm{oh}}$ \\
\hline-1 & 18.48 & 18.52 & $0.216 \%$ & 18.50 & 18.52 & $0.108 \%$ & 18.50 & 18.52 & $0.108 \%$ & 18.51 & 18.52 & $0.054 \%$ \\
\hline-0.5 & 11.49 & 11.70 & $1.828 \%$ & 11.65 & 11.70 & $0.429 \%$ & 11.69 & 11.70 & $0.086 \%$ & 11.69 & 11.70 & $0.086 \%$ \\
\hline 0 & 7.53 & 7.67 & $1.859 \%$ & 7.60 & 7.67 & $0.921 \%$ & 7.62 & 7.67 & $0.656 \%$ & 7.63 & 7.67 & $0.524 \%$ \\
\hline 0.5 & 5.25 & 5.26 & $0.190 \%$ & 5.26 & 5.26 & 0 & 5.26 & 5.26 & 0 & 5.26 & 5.26 & 0 \\
\hline 1 & 3.66 & 3.83 & $4.645 \%$ & 3.72 & 3.83 & $2.957 \%$ & 3.75 & 3.83 & $2.133 \%$ & 3.77 & 3.83 & $1.592 \%$ \\
\hline
\end{tabular}

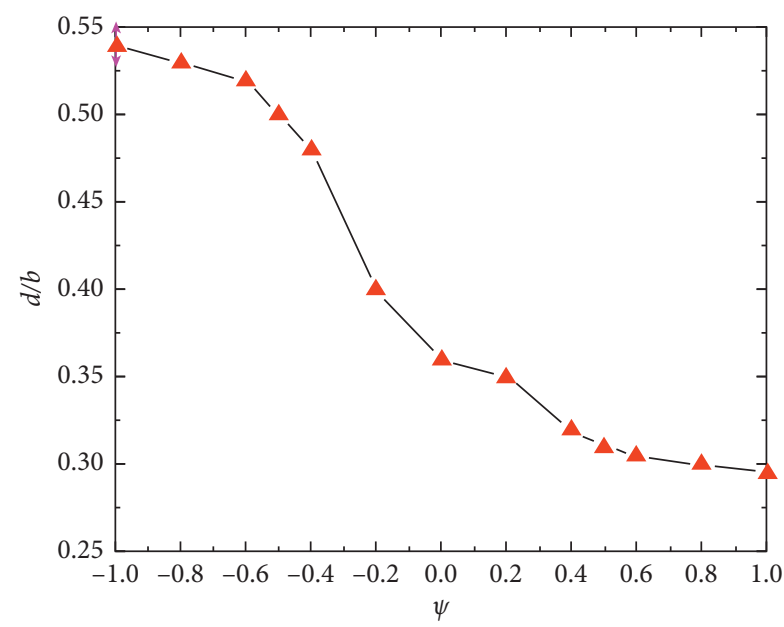

Figure 7: Critical holes sizes of change of buckling modes for different stress gradient.

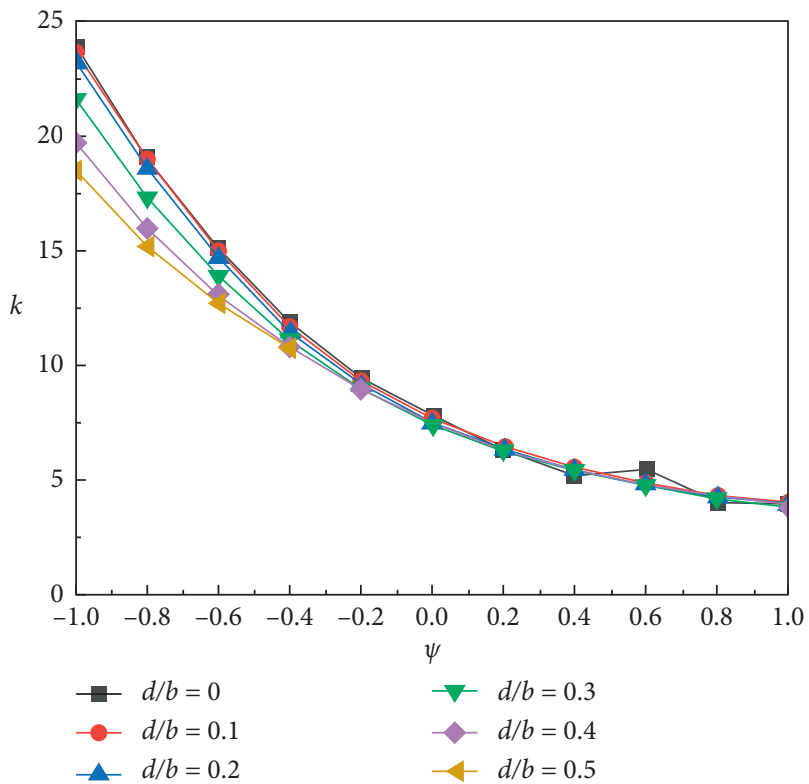

Figure 8: Buckling coefficients for plates with circular hole.

For second buckling mode, the buckling coefficient of the unstiffened strip can be obtained by using finite strip software CUFSM [29]. Figure 9 shows the relationship between the buckling coefficients of an unstiffened strip with the aspect ratio $a_{1} / b_{1}$ which increases from 0.5 to 15 for different stress gradient. The curves in Figure 9 can be fitted with equation (5) as follows.
If maximum stress acts on the stiffened edge, for $1 \geq \psi \geq 0$,

$$
k=\left(1.70-3.025 \psi+1.75 \psi^{2}\right)\left[\frac{1.63 \psi+0.88}{0.6\left(d / b_{1}\right)^{1.75}+0.003}+1\right] .
$$

If maximum stress acts on the free edge, for $\psi \geq-1$,

$$
k=\left(0.567-0.213 \psi+0.071 \psi^{2}\right)\left[\frac{0.21 \psi+1.41}{0.6\left(d / b_{1}{ }^{1.97}+0.004+1\right]},\right.
$$

where $\psi$ is the factor of nonuniform stress distribution of plate strip adjacent to the hole, and $a_{1}$ and $b_{1}$ are the length and width of plate strip adjacent to hole, respectively.

\section{Elastic Buckling of Rectangular Thin Plate with Rectangular Holes}

4.1. Thin Plate with a Single Hole. To investigate the effect of $H_{\mathrm{h}} / b$ and $L_{\mathrm{h}} / H_{\mathrm{h}}$ on the buckling mode and the buckling coefficient of the SSRPSG with a rectangular hole, the stress gradient was varied from 1 to -1 , the hole size $H_{\mathrm{h}} / b$ was ranged from 0.1 to 0.8 , the ratio of length-to-width of the hole $L_{\mathrm{h}} / H_{\mathrm{h}}$ was 1,2 , and 4 , the slenderness ratio $b / t$ was 100 , and the aspect ratio $a / b$ was 8 . Figure 10 presents the variation of deformations of the first buckling mode for perforated plate with stress gradient coefficient $\psi=-1$. The buckling coefficients of perforated plates with the hole size $H_{\mathrm{h}} / b$ equaling 0.5 are plotted in Figure 11.

4.1.1. Effects of $H_{h} / B$ Ratio. As demonstrated in Figure 10, for the plate with smaller hole $\left(H_{\mathrm{h}} / b=0.1\right)$, the rectangular hole causes a decrease of the buckling coefficient and the local buckling including the hole at the section of hole is prominent. The buckling of plate strip adjacent to hole occurs with the increase of the dimension of the hole $\left(\mathrm{H}_{\mathrm{h}} /\right.$ $b=0.2,0.3,0.4,0.5,0.6,0.7$, and 0.8).

As shown in Figure 11, the buckling coefficients of the SSRPSG with a rectangular hole predicted with equation (2) decrease firstly. For instance, the buckling coefficient decreases maximally by $30.2 \%$ for bending plate when the ratio of length-to-width of hole is equal to 1 . Then, buckling coefficients increase with the increase of the hole sizes. The results show that the effect of the rectangular hole is more than circular hole on buckling coefficient. 


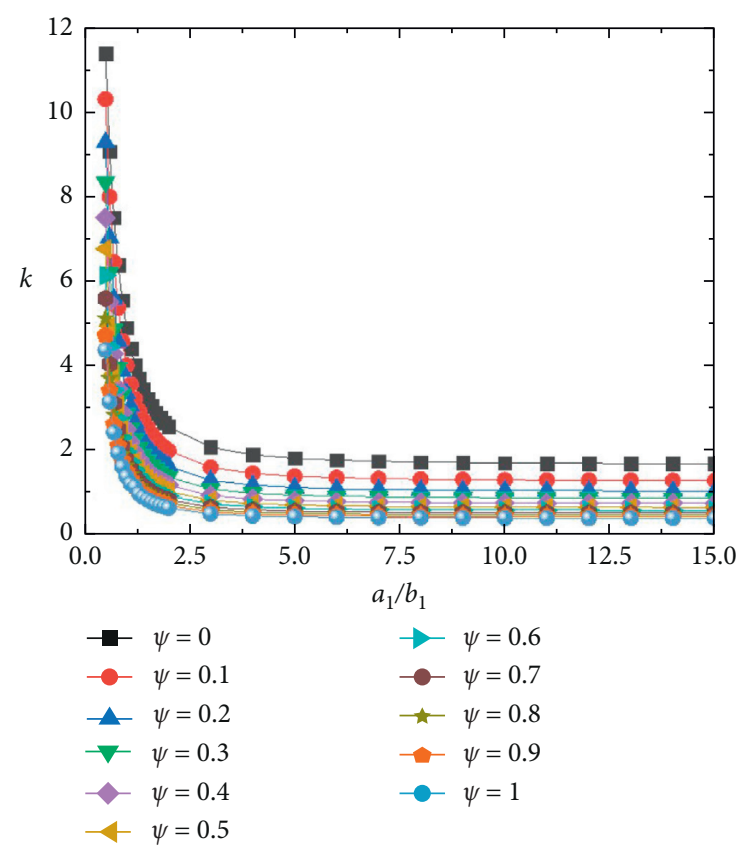

(a)

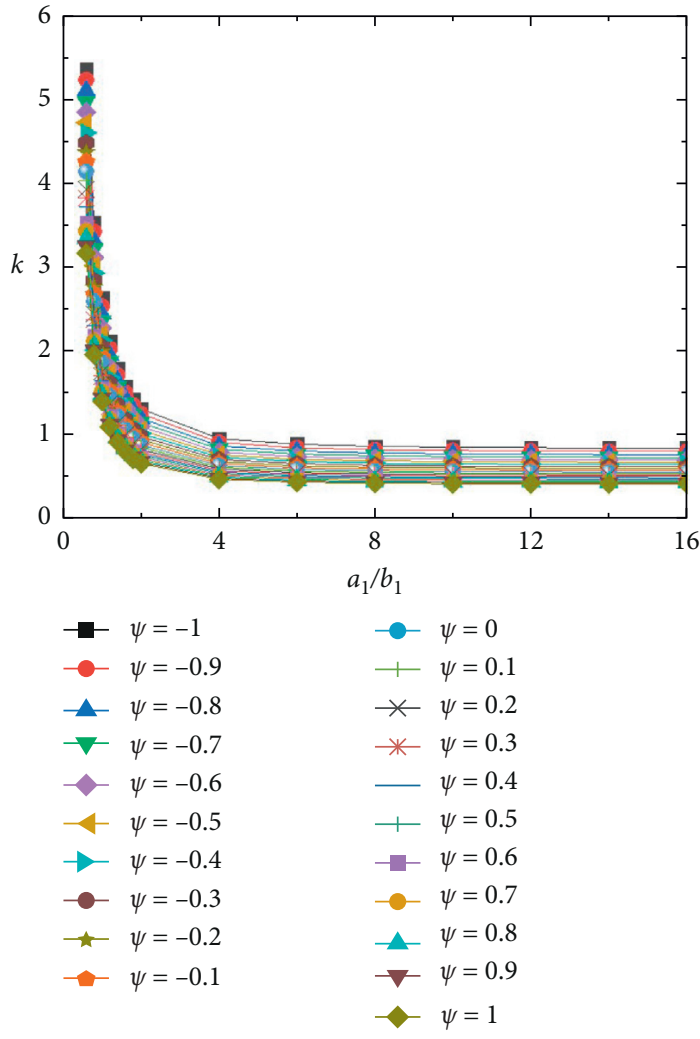

(b)

FIgURE 9: Buckling coefficient of three edge simplified-supported plate strip. (a) Maximum stress acts on the stiffened edge. (b) Maximum stress acts on the free edge.

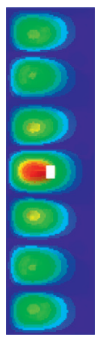

(a)

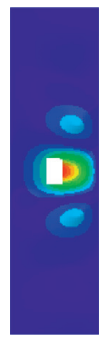

(b)

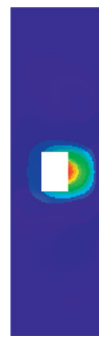

(c)

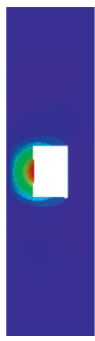

(d)

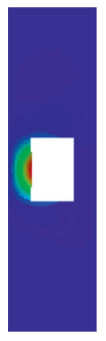

(e)

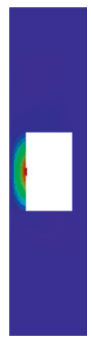

(f)

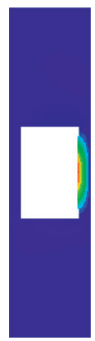

(g)

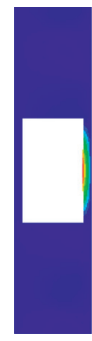

(h)

Figure 10: Buckling modes for plates with different hole sizes. (a) $\mathrm{H}_{\mathrm{h}} / b=0.1$. (b) $\mathrm{H}_{\mathrm{h}} / b=0.2$. (c) $\mathrm{H}_{\mathrm{h}} / b=0.3$. (d) $\mathrm{H}_{\mathrm{h}} / b=0.4$. (e) $\mathrm{H}_{\mathrm{h}} / b=0.5$. (f) $\mathrm{H}_{\mathrm{h}} / b=0.6$. (g) $\mathrm{H}_{\mathrm{h}} / b=0.7$. (h) $\mathrm{H}_{\mathrm{h}} / b=0.8$.

4.1.2. Effects of $L_{h} / H_{h}$ Ratio. The effects of $L_{\mathrm{h}} / H_{\mathrm{h}}$ on buckling coefficient can be found from Figure 11. It can be observed that buckling coefficients decreases significantly with the increase of the ratio of length-to-width of hole. For bending of the perforated plate shown in Figure 11(a), the buckling coefficients decrease maximally by $30.2 \%$, $46.7 \%$, and $61.25 \%$ when the ratio of length-to-width of hole is 1,2 , and 4 , respectively. For the axially compressed perforated plate shown in Figure 11(e), the buckling coefficients decrease maximally by $6.1 \%, 16.2 \%$, and $22.5 \%$ when the ratio of length-to-width of hole is 1,2 , and 4 , respectively.

\subsection{Thin Plate with Multiple Holes}

4.2.1. Effects of $\mathrm{S} / \mathrm{H}_{h}$ Ratio. Figure 12 shows the variation of the buckling coefficient for the SSRPSG with three rectangular holes, which cover a slenderness ratio $(b / t=100)$, an aspect ratio $a / b=8$, different stress gradients ( $\psi$ ranging from 1 to -1$)$, different hole sizes $\left(H_{\mathrm{h}} / b=0.1,0.3,0.5,0.7\right)$, one only ratio of length-to-width of hole $\left(L_{\mathrm{h}} / H_{\mathrm{h}}=2\right)$, and different hole spacings $\left(S / H_{\mathrm{h}}\right.$ ranging from 1 to 10$)$.

As shown in Figure 12, the buckling coefficients converge to a constant magnitude as the increase of ratio of the hole spacing to the length of the hole. The error of buckling 

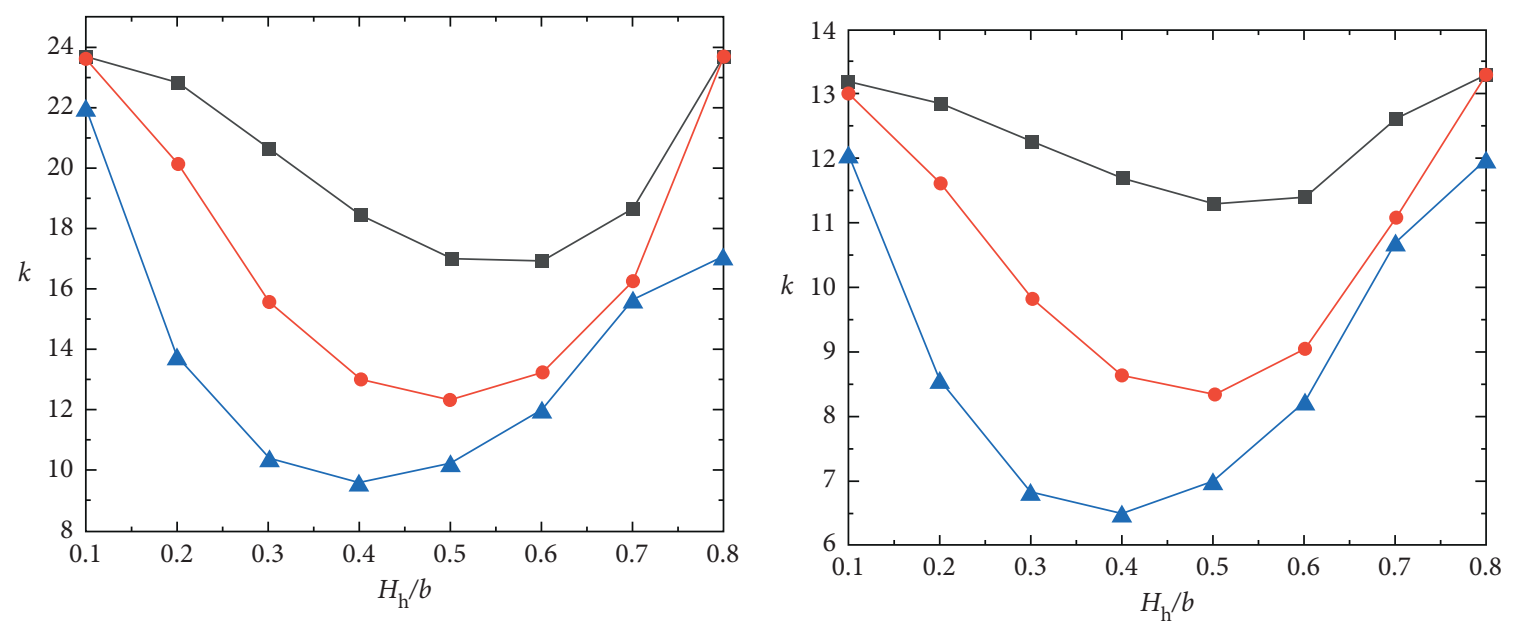

$$
\begin{aligned}
& \rightarrow L_{\mathrm{h}} / H_{\mathrm{h}}=1 \\
& \longrightarrow L_{\mathrm{h}} / H_{\mathrm{h}}=2 \\
& \longrightarrow L_{\mathrm{h}} / H_{\mathrm{h}}=4
\end{aligned}
$$$$
\begin{aligned}
& \rightarrow L_{\mathrm{h}} / H_{\mathrm{h}}=1 \\
& \rightarrow L_{\mathrm{h}} / H_{\mathrm{h}}=2 \\
& -L_{\mathrm{h}} / H_{\mathrm{h}}=4
\end{aligned}
$$

(a)

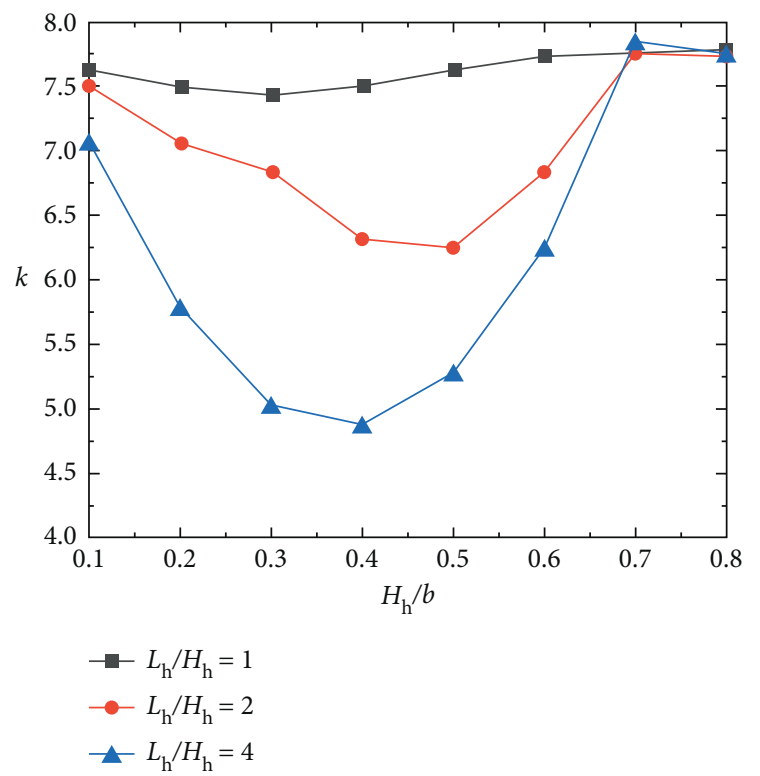

(b)

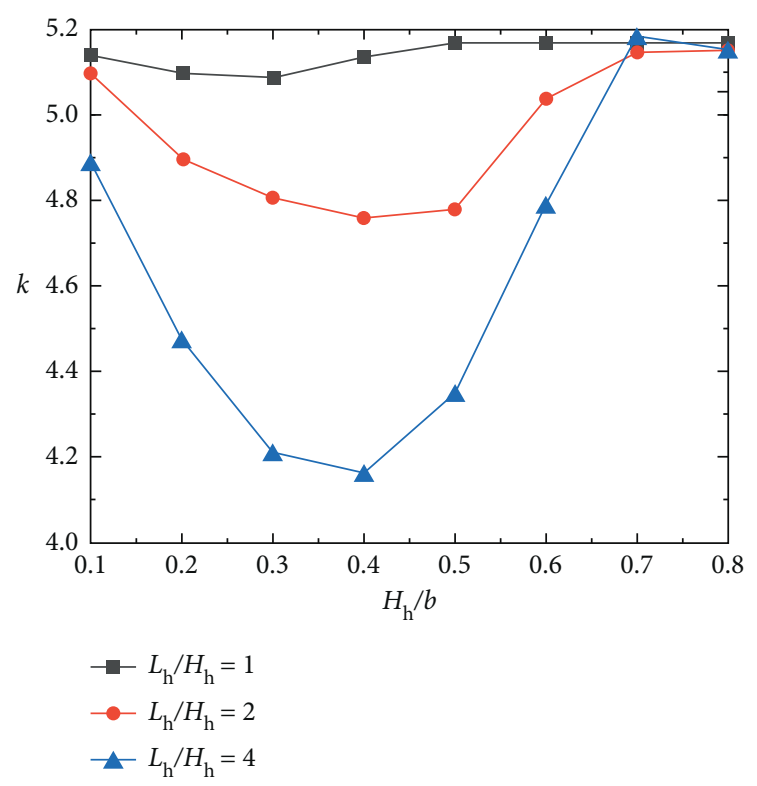

(c)

(d)

Figure 11: Continued. 


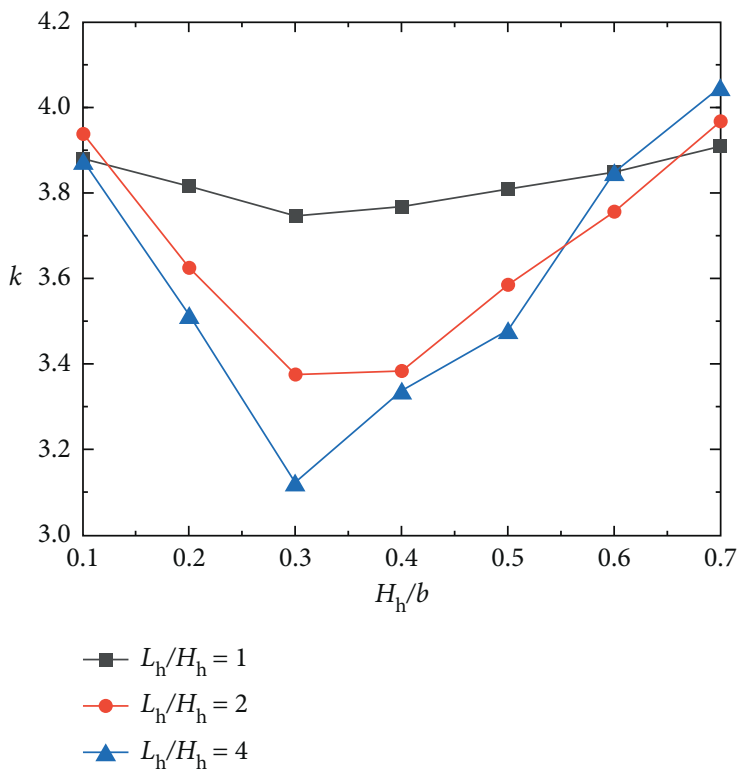

(e)

FiguRE 11: Buckling coefficients for plate with a rectangular hole for different hole sizes. (a) $\psi=-1$. (b) $\psi=-0.5$. (c) $\psi=0$. (d) $\psi=0.5$. (e) $\psi=1$.

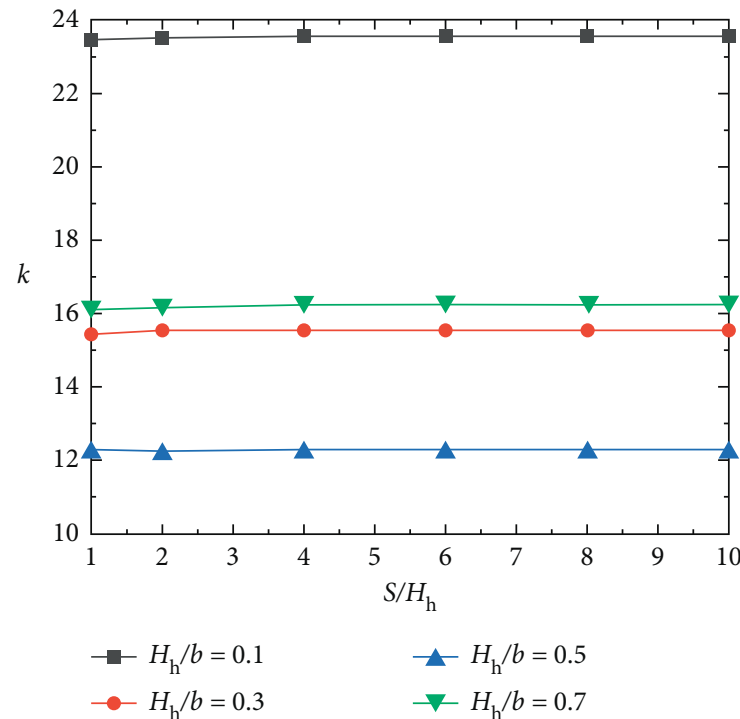

(a)

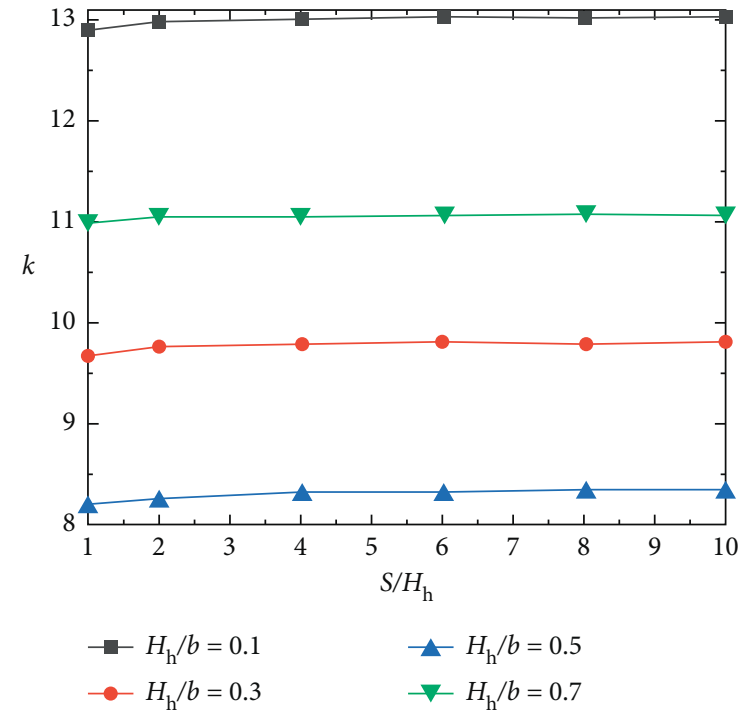

(b)

FIgURE 12: Continued. 


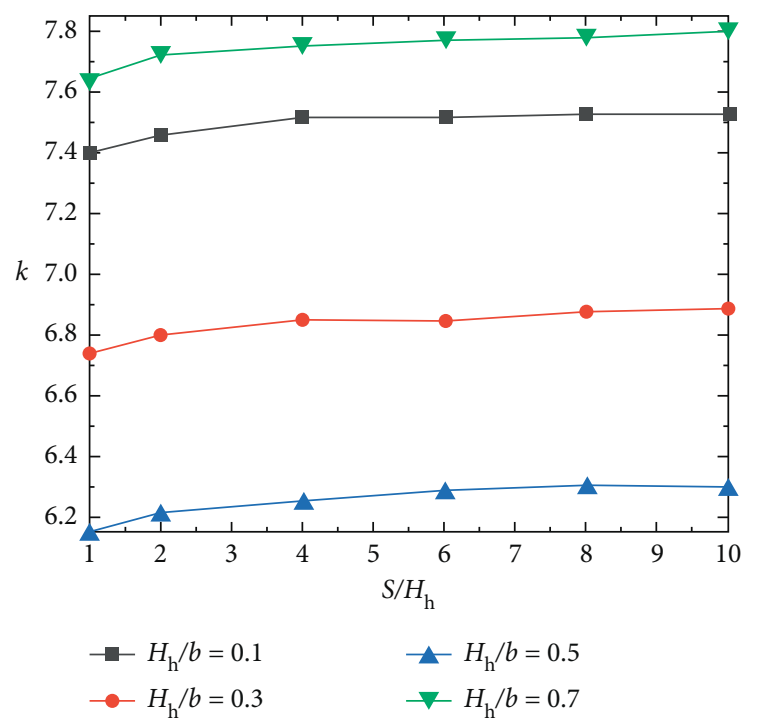

(c)

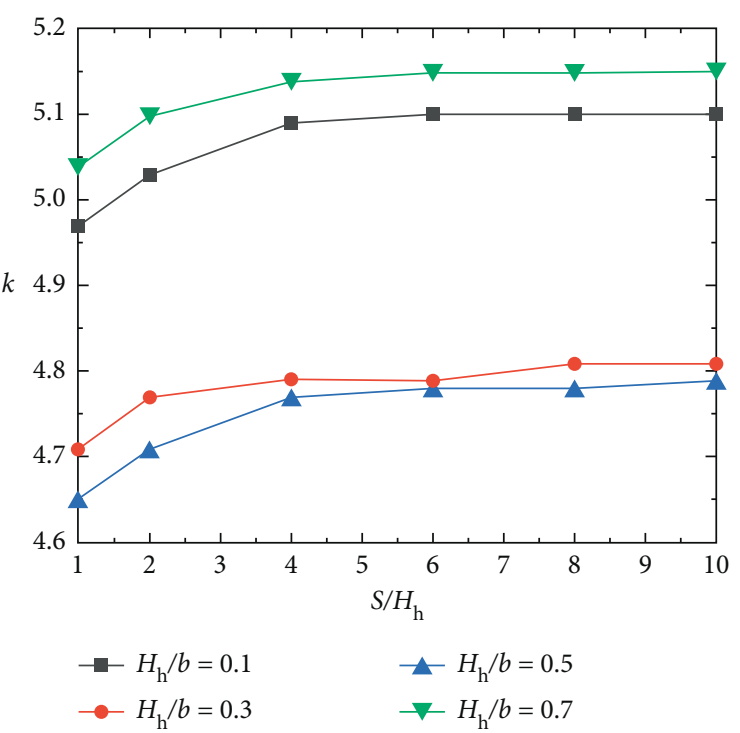

(d)

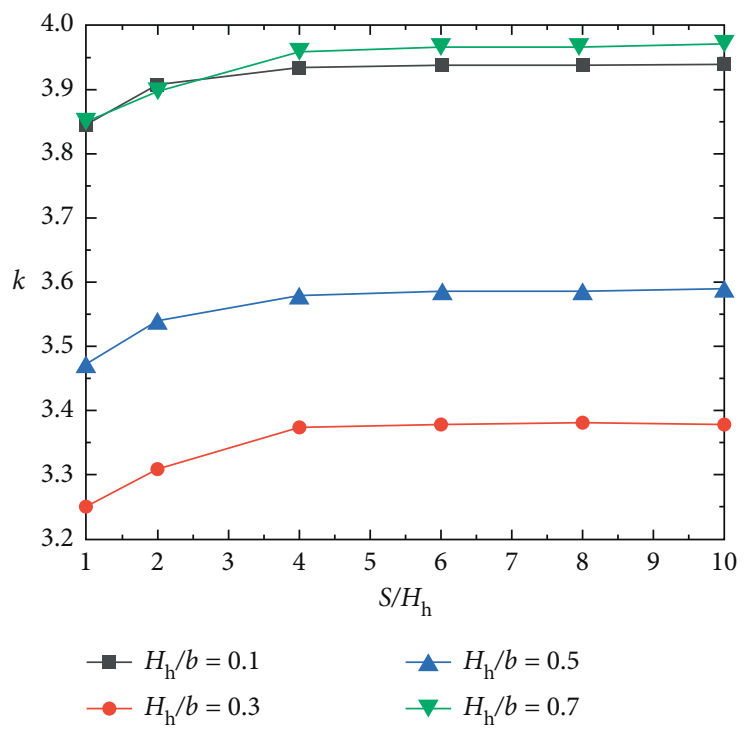

(e)

Figure 12: Buckling coefficients of plates with multiple rectangular holes for different hole sizes and spacing. (a) $\psi=-1$. (b) $\psi=-0.5$. (c) $\psi=0$. (d) $\psi=0.5$. (e) $\psi=1$.

coefficients is less than $3 \%$ when $S / H_{\mathrm{h}}$ exceeds 4 . It demonstrates that the influence of the holes spacing is slight.

4.2.2. Effects of $H_{h} / B$ Ratio. Figure 13 presents the variation of the buckling coefficient of SSRPGS with three rectangular holes, covering a slenderness ratio $(b / t=100)$, an aspect ratio $(a / b=8)$, different stress gradients ( $\psi$ ranging from 1 to -1 ), different hole sizes $\left(H_{\mathrm{h}} / b=0.1,0.3,0.5\right.$, and 0.7$)$, one single ratio of length-to-width of hole $\left(L_{\mathrm{h}} / H_{\mathrm{h}}=2\right)$, and one single hole spacing $\left(S / H_{\mathrm{h}}=4\right)$. As shown in Figure 13, the buckling coefficients of SSRPGS with rectangular holes decrease firstly, and then they increase with the increase of the hole sizes.
4.2.3. Comparison on Buckling Coefficient for Plate with Single and Multiple Rectangular Holes. The comparison on the buckling coefficient between a plate with one rectangular hole and a plate with three rectangular holes is presented in Table 5. The current comparison covers the hole size $\left(H_{\mathrm{h}} / b=0.5\right)$, hole spacing $\left(S / H_{\mathrm{h}}=4\right)$, and the ratio of length-to-width of hole $\left(L_{\mathrm{h}} / H_{\mathrm{h}}=2\right)$. It can be observed from Table 5 that the buckling coefficients for the plate with three rectangular holes and the plate with one rectangular hole are almost the same. The comparison indicates that the buckling coefficient can be predicted by assuming $S / H_{\mathrm{h}}=4$ when $S / H_{\mathrm{h}}$ exceeds 4 for the SSRPSG with multiple rectangular holes. 


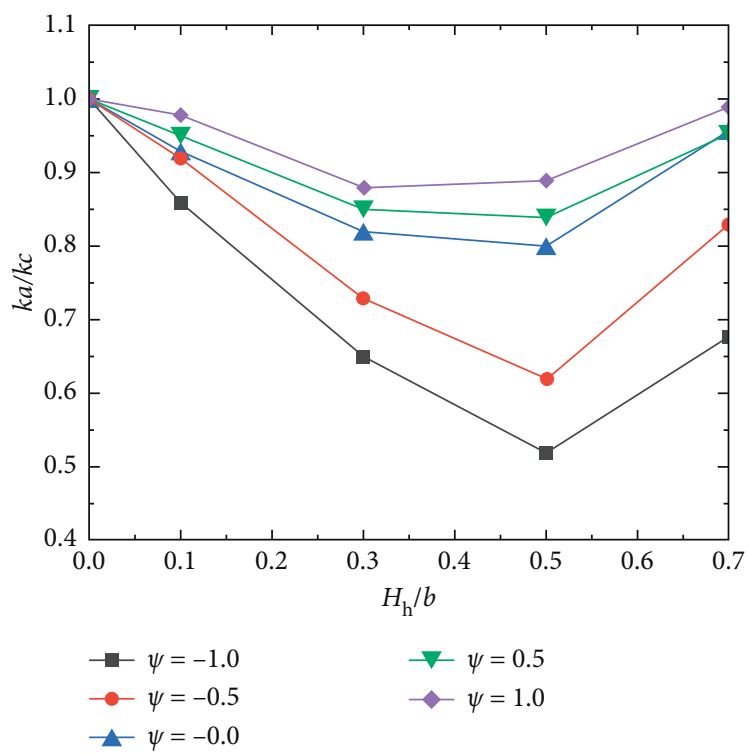

FIGURE 13: Buckling coefficients of plates with multiple rectangular holes for different hole sizes.

TABLE 5: Comparison on buckling coefficients for plate with single hole and multiple holes.

\begin{tabular}{lcccccccccccc}
\hline & \multicolumn{3}{c}{$\mathrm{S} / \mathrm{H}_{\mathrm{h}}=4$} & \multicolumn{3}{c}{$\mathrm{S} / H_{\mathrm{h}}=6$} & \multicolumn{3}{c}{$\mathrm{S} / H_{\mathrm{h}}=8$} & \multicolumn{3}{c}{$\mathrm{S} / H_{\mathrm{h}}=10$} \\
& $k_{\mathrm{mh}}$ & $k_{\mathrm{oh}}$ & $k_{\mathrm{mh}} / k_{\mathrm{oh}}$ & $k_{\mathrm{mh}}$ & $k_{\mathrm{oh}}$ & $k_{\mathrm{mh}} / k_{\mathrm{oh}}$ & $k_{\mathrm{mh}}$ & $k_{\mathrm{oh}}$ & $k_{\mathrm{mh}} / k_{\mathrm{oh}}$ & $k_{\mathrm{mh}}$ & $k_{\mathrm{oh}}$ & $k_{\mathrm{mh}} / k_{\mathrm{oh}}$ \\
\hline-1 & 12.31 & 12.33 & 1.00 & 12.32 & 12.33 & 1.00 & 12.32 & 12.33 & 1.00 & 12.33 & 12.33 & 1.00 \\
-0.5 & 8.32 & 8.33 & 1.00 & 8.32 & 8.33 & 1.00 & 8.33 & 8.33 & 1.00 & 8.33 & 8.33 & 1.00 \\
0 & 6.25 & 6.26 & 1.00 & 6.29 & 6.26 & 1.00 & 6.30 & 6.26 & 1.01 & 6.30 & 6.26 & 1.01 \\
0.5 & 4.77 & 4.78 & 1.00 & 4.78 & 4.78 & 1.00 & 4.78 & 4.78 & 1.00 & 4.79 & 4.78 & 1.00 \\
1 & 3.58 & 3.59 & 1.00 & 3.58 & 3.59 & 1.00 & 3.59 & 3.59 & 1.00 & 3.59 & 3.59 & 1.00 \\
\hline
\end{tabular}

4.3. Proposed Buckling Coefficient Equations. The buckling mode of the SSRPGS with rectangular holes can change from the local buckling including the hole (see Figure 10(a)) to the buckling of the plate strip adjacent to a hole (see Figure 10(e)), as shown in Figure 10. The relationship between the critical hole size when buckling modes change and the stress gradient can be obtained based on the finite-element analysis and plotted in Figure 14. The critical hole size of change of buckling modes can be expressed as equation (6) which is obtained according to fitted curves in Figure 14:

$$
\begin{aligned}
H_{h} / b & =-0.017\left(L_{h} / H_{h}\right)^{2}+0.08\left(L_{h} / H_{h}\right)+0.02 \psi^{2} \\
& -0.14 \psi+0.42 .
\end{aligned}
$$

So, the buckling coefficient of the SSRPSG with rectangular holes should be predicted considering two cases which correspond to two buckling modes: (1) the buckling including the hole when the hole size is less than the value indicated in equation (6) and the plate should be considered as a stiffened plate with hole; (2) buckling of the plate strip adjacent to hole when the hole size is more than the value indicated in equation (6) and the plate strip should be considered as a unstiffened plate.

(1) For the first buckling mode, the buckling coefficient of the stiffened plate with hole can be obtained from FE analysis. For instance, the buckling coefficients of

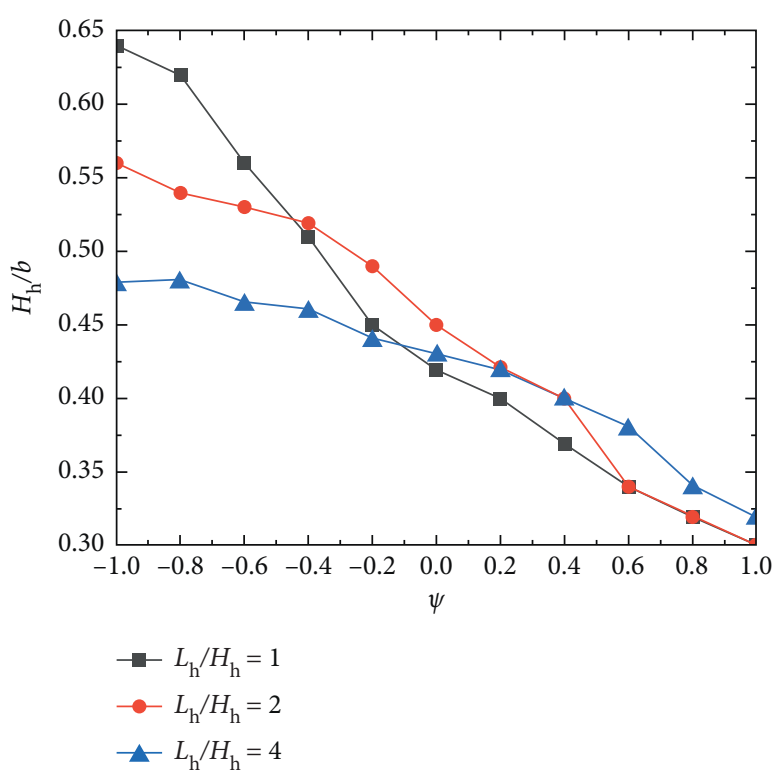

FIgURE 14: Critical hole sizes of change of buckling modes for different stress gradient.

the stiffened plate with the ratio of height to length of the rectangular hole equaling to 1 are plotted in Figure 15. 


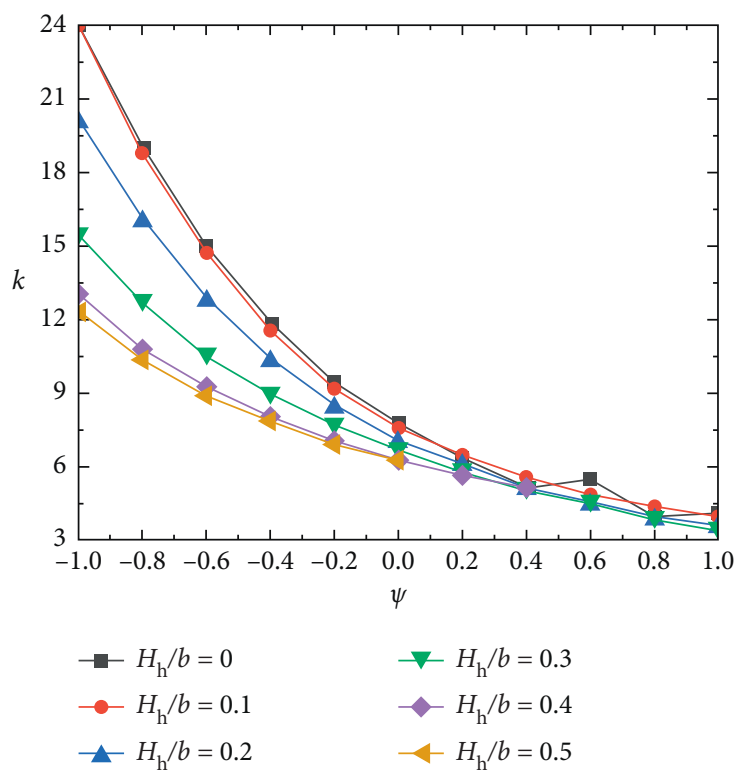

FIgURE 15: Buckling coefficients for plate with rectangular hole $\left(L_{h} / H_{\mathrm{h}}=1\right)$.

The $H_{\mathrm{h}} / b, L_{\mathrm{h}} / H_{\mathrm{h}}$, and $\psi$ are the primary parameters affecting the buckling coefficient as shown in Figure 15. Therefore, the buckling coefficients of the stiffened plate with rectangular hole under stress gradient can be calculated using equation (7) which is obtained according to fit the curves in Figure 15:

$$
k=\left\{\begin{array}{l}
\left(7.8-6.29 \psi+9.78 \psi^{2}\right) \times\left[0.27\left(H_{h} / b\right)^{2}-0.06\left(L_{h} / H_{h}\right)^{2}\left(H_{h} / b\right)+0.37 \psi\left(H_{h} / b\right)+0.03\left(H_{h} / b\right)+1\right], \quad-1 \leq \psi \leq 0 \\
\left(7.8-8.15 \psi+4.35 \psi^{2}\right) \times\left[5.91\left(H_{h} / b\right)^{2}-0.017\left(L_{h} / H_{h}\right)^{2}\left(H_{h} / b\right)-1.87 \psi\left(H_{h} / b\right)+0.98\left(H_{h} / b\right)+1\right], \quad 0<\psi \leq 1 .
\end{array}\right.
$$

(2) For second buckling mode, the buckling coefficient of the unstiffened strip can be predicted by using equation (5) and $d$ is replaced with $L_{\mathrm{h}}$.

\section{Effective Width for Perforated Rectangular Thin Plate under Stress Gradient}

5.1. Proposed Effective Width Method. The effective width method is an efficient means to represent the post-local buckling nonuniform stress distribution and used to predict the ultimate strength of cold-formed steel elements and members in many codes. Based on the developed buckling coefficient equations, the ultimate strength of the SSRPGS with circular or rectangular holes can be calculated by using the effective width method in Chinese code Technical code for cold-formed thin-walled steel structures (GB50018-2002). The effective width is calculated by using equation (8). However, we need to note that the ultimate strength of the SSRPSG with circular or rectangular holes should be limited by the strength of the effective net cross section:

$$
\frac{b_{e}}{t}= \begin{cases}\frac{b_{c}}{t}, & \frac{b}{t} \leq 18 \alpha \rho, \\ \left(\sqrt{\frac{21.8 \alpha \rho}{b / t}}-0.1\right) \frac{b_{c}}{t}, & 18 \alpha \rho<\frac{b}{t}<38 \alpha \rho, \\ \frac{25 \alpha \rho}{b / t} \cdot \frac{b_{c}}{t}, & \frac{b}{t} \geq 38 \alpha \rho,\end{cases}
$$

where $b_{\mathrm{c}}$ is the width of compressed zone for the perforated plate as shown in Figure 14, $d$ in Figure 14 can be replaced by $H_{\mathrm{h}}$ for the plate with rectangular holes, $t$ is the thickness of plate, $\alpha=1.15-0.15 \psi, \rho=\sqrt{235 k_{1} k / \sigma_{1}}, \sigma_{1}$ is the maximum compressed stress for the compressed zone of plate, $k_{1}$ is the coefficient of interaction buckling, and $k$ is the buckling coefficient of plate considering the effect of hole and can be predicted with equations (4), (5), and (7).

The effective width distribution $\left(b_{\mathrm{e} 1}, b_{\mathrm{e} 2}\right)$ for effective width $\left(b_{\mathrm{e}}\right)$ of perforated plates is determined as shown in Figure 16, where $b_{\mathrm{e} 1}$ and $b_{\mathrm{e} 2}$ are calculated by using formulas in Technical code for cold-formed thin-walled steel structures (GB50018-2002). 


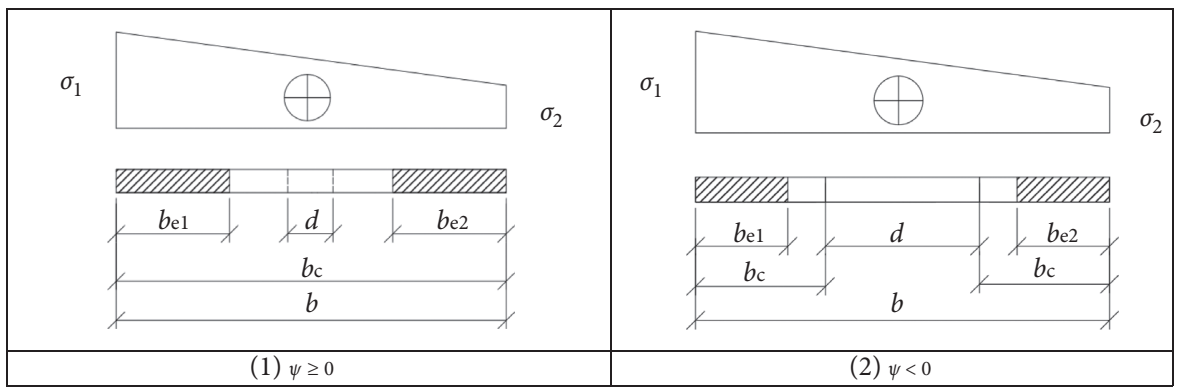

(a)

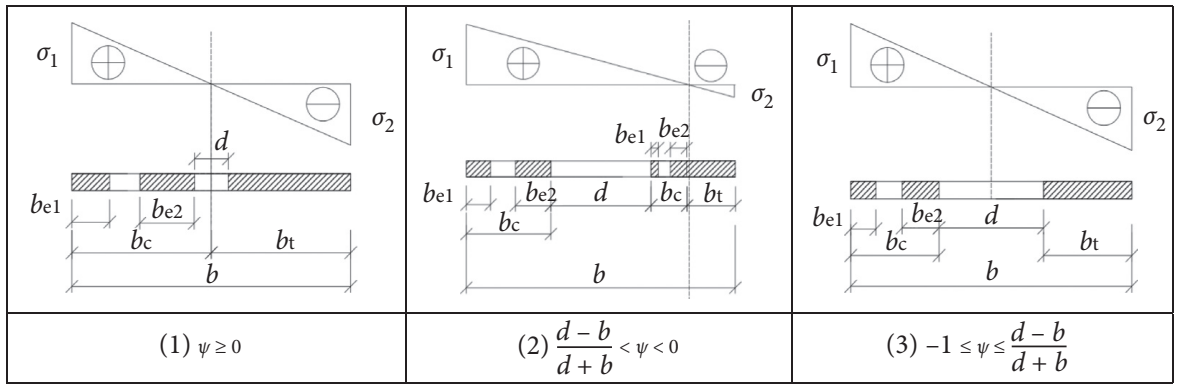

(b)

FIGURE 16: Effective width distribution of perforated plate. (a) The plate with smaller holes. (b) The plate with larger holes.

\subsection{Strength of Perforated Thin Plates under Stress Gradient}

5.2.1. Thin Plates with Circular Holes. The comparison on ultimate strength of the SSRPGS with a circular hole between the proposed effective width method and FE analysis is presented in Figure 17. The calculated and FE analysis results are plotted using solid lines and scatters. $M_{\mathrm{y}}$ and $N_{\mathrm{y}}$ are yield strength of gross sections, and $M$ and $N$ are ultimate strength by using proposed effective width method and FE analysis. The current comparison covers the perforation plate with aspect ratio $a / b=3$, different slenderness ratios $(b / t$ ranging from 20 to 200 ), different hole sizes ( $d / b$ ranging from 0.1 to 0.8 ), and different loading cases ( $\psi$ ranging from 1 to -1 ).

Figure 17 shows that the ratio of the ultimate strength to yield strength of gross section decreases with the increase of slenderness ratio of the SSRPSG with a circular hole. The hole size has a negligible effect on the ultimate strength of the perforated plate when the hole diameter is low, while the effect gradually increases with the increase of the hole sizes. Meanwhile, the perfect consistency is obtained between results calculated by using the proposed effective width method and FE analysis results, which means that the proposed effective width method presented in this paper is accurate and reliable.

5.2.2. Thin Plate with a Rectangular Hole. The comparison on ultimate strength of the SSRPSG with a rectangular hole between the proposed effective width method and FE analysis is presented in Figure 18. The comparison covers the perforation plate with aspect ratio $a / b=3$, the ratio of length-to-width of hole $L_{\mathrm{h}} / H_{\mathrm{h}}=2$, different slenderness ratios ( $b / t$ ranging from 20 to 200$)$, different hole sizes $\left(H_{\mathrm{h}} / b\right.$ ranging from 0.1 to 0.8$)$, and different loading cases $(\psi$ ranging from 1 to -1 ).
The same conclusion can be observed for the plate with rectangular as the plate with circular hole from Figure 18. The perfect consistency is obtained between results calculated using the proposed effective width method and FE analysis results, which identifies that the proposed effective width method presented in this paper is accurate and reliable.

5.3. Reliability Analysis for Ultimate Strength of Perforated Thin Plates under Stress Gradient. The ratios of ultimate capacities for the SSRPSG with circular and rectangular holes between the results $\left(M_{\mathrm{d}}, N_{\mathrm{d}}\right)$ predicted by using the proposed effective width method and the FE analysis results $\left(M_{\mathrm{a}}, N_{\mathrm{a}}\right)$ are presented in Figure 19.

The statistical results (mean values and coefficients of variation $(\mathrm{CoV}))$ of the predicted-to-FE strength ratio $\left(M_{\mathrm{d}} /\right.$ $M_{\mathrm{a}}$ and $N_{\mathrm{d}} / N_{\mathrm{a}}$ ) are presented in Table 6 . The mean value and CoV are 0.99167 and 0.01472 , respectively. It can be concluded from Table 6 and Figure 19 that the effective design width method based on the proposed buckling coefficients gives good and safe predictions for the ultimate strength of the SSRPGS with a circular or rectangular hole.

\section{Effective Design Width For Cold-Formed Steel Members with Web Openings}

The suitability of the proposed effective width method for the SSRPSG with circular or rectangular holes is further verified by comparing the predicted ultimate strength with the test results given by Sivakumaran [2], Moen and Schafer [4], He and Zhao [5], Yao, Guo, and Song [30], Xu, Shi, and Yang [31], Pu,Beale, and Lau [32], Miller and Peköz [33] for 


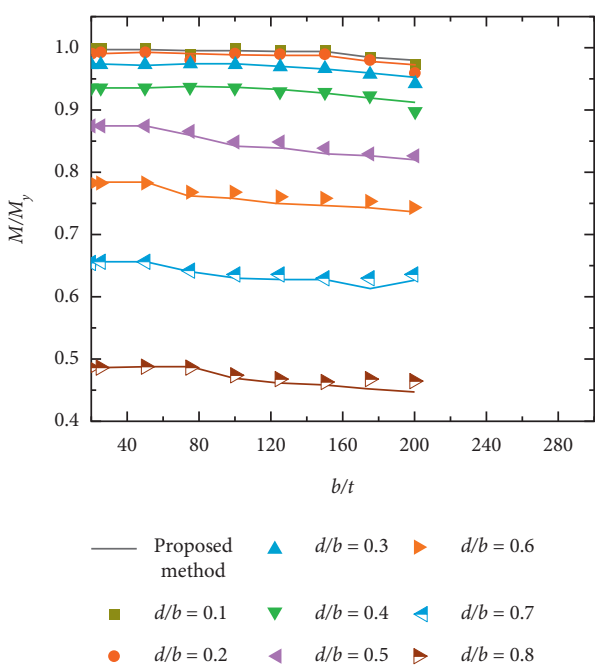

(a)

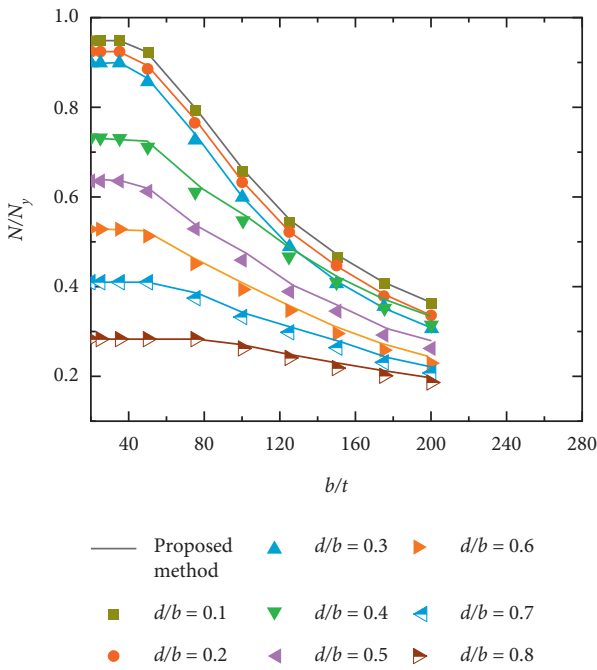

(c)

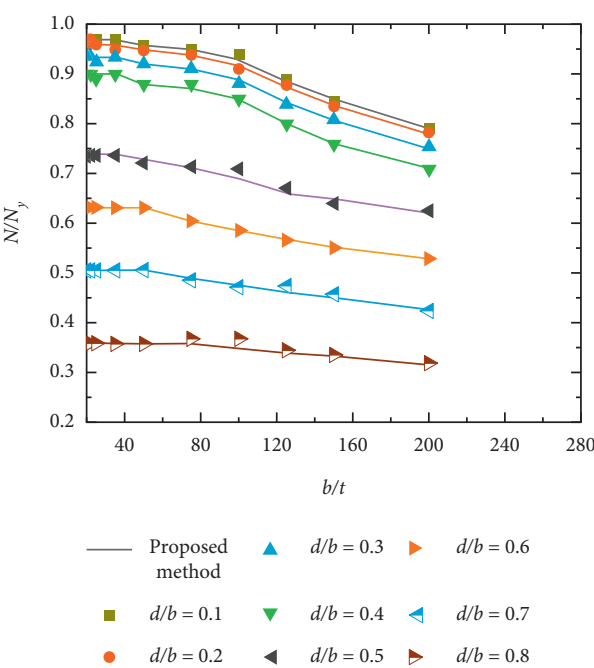

(b)

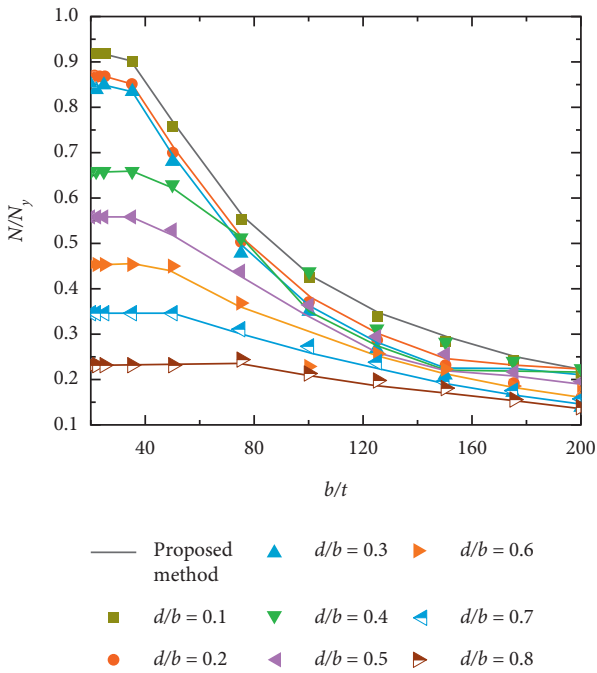

(d)

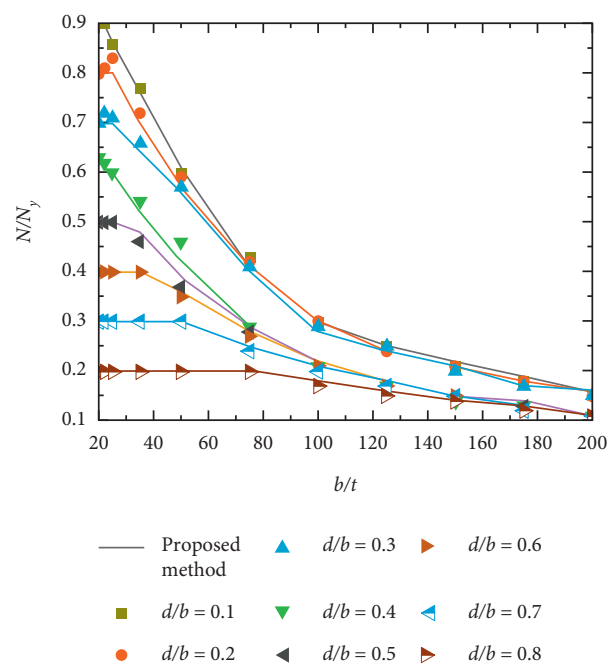

(e)

FIGURE 17: Comparison on ultimate strength of plates with a circular hole between predicted results by using the effective width method and FE results. (a) $\psi=-1$. (b) $\psi=-0.5$. (c) $\psi=0$. (d) $\psi=0.5$. (e) $\psi=1$. 


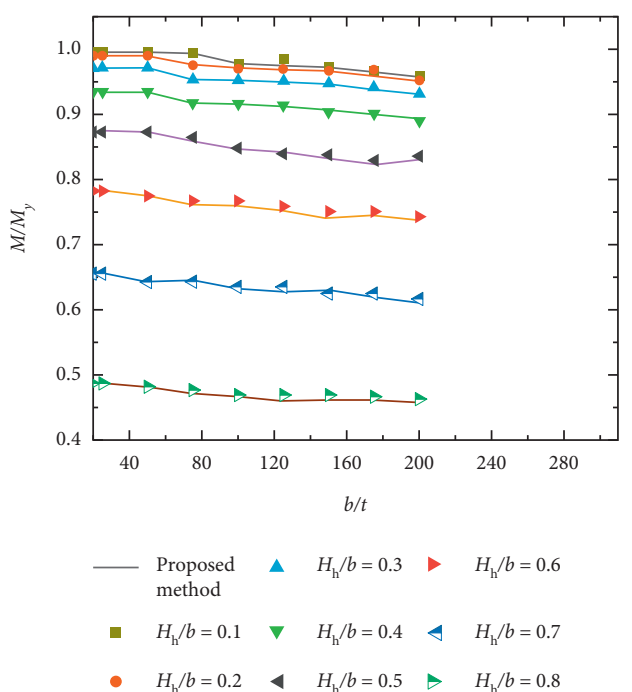

(a)

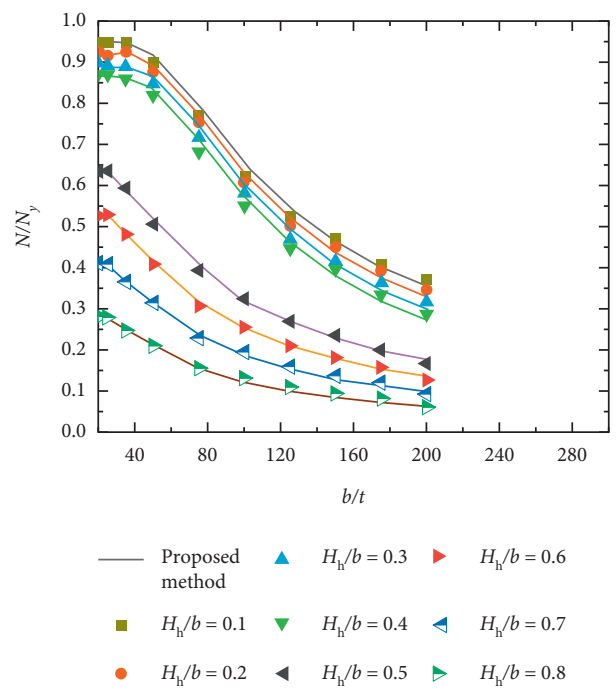

(c)
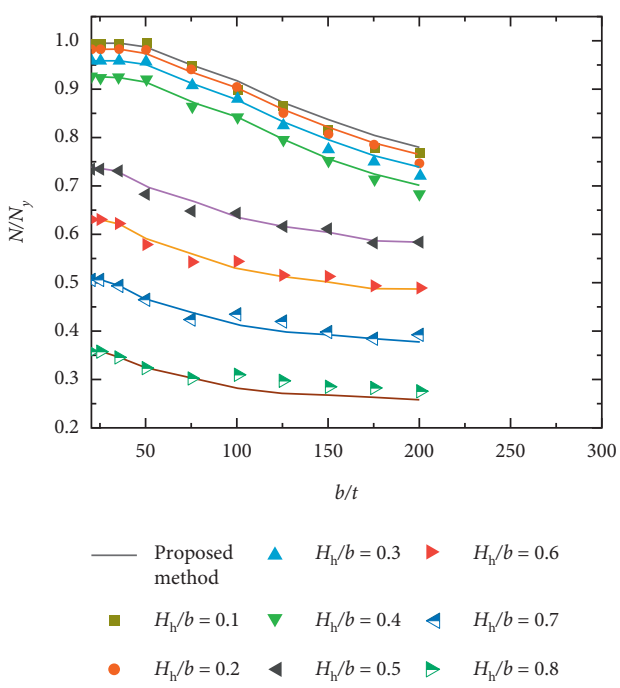

(b)

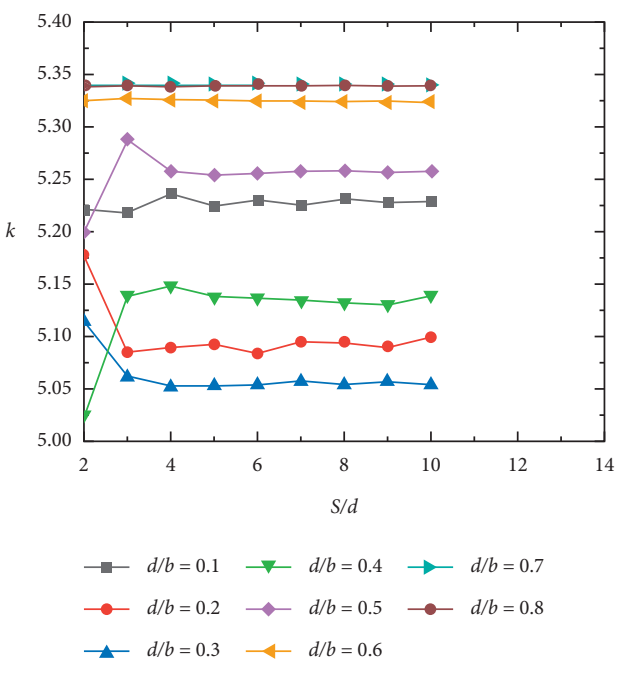

(d)

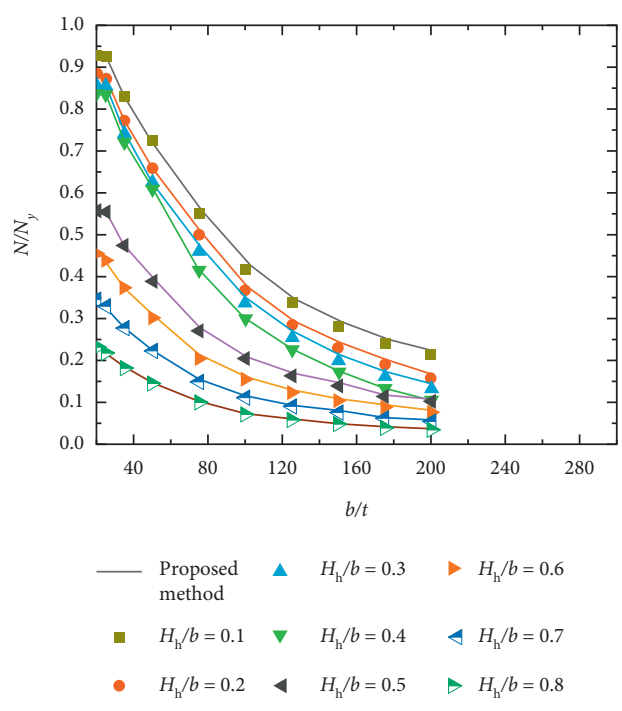

(e)

FIGURE 18: Comparison on ultimate strength of plates with a rectangular hole between predicted results by using the effective width method and FE results. (a) $\psi=-1$. (b) $\psi=-0.5$. (c) $\psi=0$. (d) $\psi=0.5$. (e) $\psi=1$. 


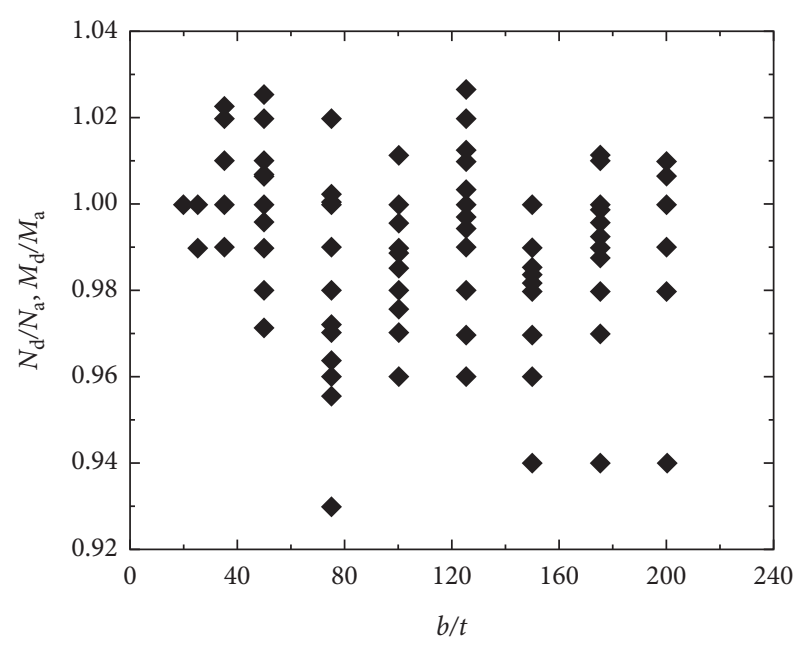

FIGURE 19: Comparison on ultimate strength between the proposed effective width method and the FE method.

TABLE 6: Statistical analysis on comparison on ultimate strength between the proposed effective width method and the FE method.

\begin{tabular}{lcccccc}
\hline$\psi$ & -1 & -0.5 & 0 & 0.5 & 1 & \\
$n$ & 80 & 80 & 80 & 80 & 80 & 400 \\
$\begin{array}{l}\text { Ultimate } \\
\text { strength }\end{array}$ & $M_{\mathrm{d}} /$ & $N_{\mathrm{d}} / N_{\mathrm{a}}$ & $N_{\mathrm{d}} / N_{\mathrm{a}}$ & $N_{\mathrm{d}} / N_{\mathrm{a}}$ & $N_{\mathrm{d}} / N_{\mathrm{a}}$ & \\
\hline $\begin{array}{l}\text { Mean } \\
\text { Standard }\end{array}$ & 0.9841 & 0.9938 & 0.9954 & 0.9932 & 0.9921 & 0.9917 \\
deviation & 0.0005 & 0.0001 & 0.0001 & 0.00021 & 0.0002 & 0.0002 \\
CoV & 0.0120 & 0.0219 & 0.0089 & 0.0144 & 0.0157 & 0.0147 \\
\hline
\end{tabular}

TABle 7: Statistical for comparison between predicted and test ultimate loads for perforated studs.

\begin{tabular}{lcccc}
\hline Study & Number & Hole size & Mean & SD \\
\hline Yao et al [30] & 24 & Circular & 0.9617 & 0.0195 \\
He and Zhao [5] & 42 & Circular & 0.9573 & 0.0134 \\
Sivakumaran [2] & 18 & Circular & 0.9702 & 0.0155 \\
Mean and Schafer [4] & 12 & Slotted & 0.9687 & 0.0162 \\
Xu et al [31] & 15 & Slotted & 0.9647 & 0.0106 \\
Sivakumaran [2] & 18 & Square & 0.9625 & 0.0140 \\
Pu et al. [32] & 30 & Square & 0.9630 & 0.0144 \\
Yao et al. [30] & 24 & Rectangular & 0.9542 & 0.0148 \\
Miller and Peköz [33] & 20 & Rectangular & 0.9610 & 0.0121 \\
\hline
\end{tabular}

TABle 8: Statistical for comparison between predicted and test ultimate loads for perforated beams.

\begin{tabular}{lcccc}
\hline Study & Number & Hole size & Mean & SD \\
\hline Zhao et al. [10] & 5 & Rectangular & 0.9481 & 0.0122 \\
$\begin{array}{l}\text { Moen, Schudlic, and } \\
\text { Heyden [8] }\end{array}$ & 6 & Rectangular & 0.9523 & 0.0147 \\
\hline
\end{tabular}

axially compressed studs, and Zhao et al. [10] and Moen, Schudlic, and Heyden [8] for beams.

The predicted ultimate loads $P_{\mathrm{p}}$ by using the proposed effective width method and the experimental ultimate loads $P_{\mathrm{t}}$ for each study were presented in reference [34]. The ratios between the experimental ultimate loads and predicted ultimate loads $\left(P_{\mathrm{p}} / P_{\mathrm{t}}\right)$ were also presented in this reference. The means and standard deviations (SDs) of the ratios $\left(P_{\mathrm{p}} /\right.$ $P_{\mathrm{t}}$ ) for all tests are summarized in Tables 7 and 8 for axially compressed studs and beams, respectively. It is clearly evident from Tables 7 and 8 that the proposed effective design width method gives accurate and safe predictions of the ultimate loads.

\section{Conclusion}

This paper investigates the buckling behavior, buckling coefficient, and effective width design method of the SSRPSG with circular or rectangular holes by using a proven FE model. The effects of the slenderness ratio and the aspect ratio of plate, hole size, and hole spacing are assessed. The following conclusions and recommendations can be outlined.

The elastic buckling results obtained from the FE parametric study show that the buckling coefficients of the SSRPSG with circular or rectangular holes are less affected by the aspect ratio and the slenderness ratio. When the hole spacing is more than $4 d$ or $4 H_{\mathrm{h}}$, the effect of the spacing between holes can be negligible and the buckling coefficient for the plate with multiple holes can be calculated as in the case of a plate with one hole. With the increase of the dimension of the hole, the buckling mode of perforated SSRPSG changes from the local buckling including hole to the buckling of plate strip adjacent to the hole. The buckling coefficient of perforated plate gradually decreases, and subsequently, it increases with the increase of the dimension of the hole.

The new and improved buckling coefficient equations for the SSRPSG with circular or rectangular holes are developed based on the FE analysis. The buckling coefficients are predicted considering two buckling states: local buckling of SSRPSG including hole and buckling of the three-edge simply supported unstiffened plate strip adjacent to the hole. The predicted equations for the critical hole size of change of buckling modes are developed.

The improved effective width design method based on developed buckling coefficient equations is put forward in this paper. The perfect consistency is obtained between FE analysis and predicted results by using the proposed effective width method in terms of the ultimate strength. The mean value and $\mathrm{CoV}$ for variation of the predicted-to-finite-element strength ratio are 0.99167 and 0.01472 for 400 SSRPSG with circular or rectangular holes. The results show that the proposed effective width design method can closely predict the load capacity of the perforated plates under stress gradients.

A reliability analysis was carried out for the test perforated stud and beam to evaluate the proposed effective width design method. The results show that the proposed effective width design method can closely predict the load capacities of the perforated members. Research results will provide local buckling theoretical support system for coldformed steel perforated members, improve design standards of the cold-formed steel members, and promote its widely use in the field of constructional steel structure. 


\section{Data Availability}

The data used to support the findings of this study are included within the article (Figures 14-16 and Table 6).

\section{Conflicts of Interest}

The authors declare that there are no conflicts of interest regarding the publication of this paper.

\section{Acknowledgments}

The authors are grateful to the financial support provided by the National Natural Science Foundation Projects of China (grant no. 51868049), Natural Science Foundation Projects of Jiangxi Province in China (grant no. 20181BAB206040), and Department of Education Science and Technology Projects of Jiangxi Province in China (grant no. GJJ180932 and GJJ170983).

\section{References}

[1] R. A. Ortiz-Colberg, The Load Carrying Capacity of Perforated Cold-Formed Steel Columns, Cornell University, New York, NY, USA, 1981.

[2] K. S. Sivakumaran, "Load capacity of uniformly compressed cold-formed steel section with punched web," Canadian Journal of Civil Engineering, vol. 14, no. 4, pp. 550-558, 1987.

[3] N. Abdel-Rahman, Cold-formed Steel Compression Members with Perforations, McMaster University, Hamilton, Canada, 1997.

[4] C. D. Moen and B. W. Schafer, "Experiments on cold-formed steel columns with holes," Thin-Walled Structures, vol. 46, no. 10, pp. 1164-1182, 2008.

[5] B. He and G. Zhao, "Analysis on buckling behavior of coldformed lipped channel with perforated web," Journal of Journal of Construction Engineering and Management, vol. 21, no. 1, pp. 1-9, 1989, In Chinese.

[6] Y. Yao, Z. Wu, B. Cheng et al., "Experimental investigation into axial compressive behavior of cold-formed thin-walled steel columns with lipped channel and openings," South China University of Technology, vol. 39, no. 9, pp. 61-67, 2011, In Chinese.

[7] C. D. Moen and B. W. Schafer, "Direct strength method for design of cold-formed steel columns with holes," Journal of Structural Engineering, vol. 137, no. 5, pp. 559-570, 2016.

[8] C. D. Moen, A. Schudlich, and A. Von Der Heyden, "Experiments on cold-formed steel C-section joists with unstiffened web holes," Journal of Structural Engineering, vol. 139, no. 5, pp. 695-704, 2013.

[9] J. Zhao, K. Sun, C. Yu, and J. Wang, "Tests and direct strength design on cold-formed steel channel beams with web holes," Engineering Structures, vol. 184, pp. 434-446, 2019.

[10] J. Zhao, P. Gao, J. Wang et al., "Local buckling behavior and direct strength method of cold-formed steel channel beams with web rectangular openings and complex edge stiffeners," Journal of Building Materials and Structures, vol. 41, no. 6, pp. 195-204, 2020, In Chinese.

[11] C. D. Moen and B. W. Schafer, "Elastic buckling of coldformed steel columns and beams with holes," Engineering Structures, vol. 31, no. 12, pp. 2812-2824, 2009.

[12] X. Yao, Y. Guo, Y. Liu et al., "Analysis on distortional buckling of cold-formed thin-walled steel lipped channel steel members with web openings under axial compression," Indian Concrete Journal, vol. 50, no. 1, pp. 170-177, 2020, In Chinese.

[13] K. M. El-Sawy and A. S. Nazmy, "Effect of aspect ratio on the elastic buckling of uniaxially loaded plates with eccentric holes," Thin-Walled Structures, vol. 39, no. 12, pp. 983-998, 2001.

[14] C. J. Brown and A. L. Yettram, "Factors influencing the elastic stability of orthtropic plates containing a rectangular cut out," The Journal of Strain Analysis for Engineering Design, vol. 35, no. 6, pp. 361-371, 2000.

[15] M. K. Aydin and M. Sonme, "Elastic buckling of rectangular plates under linearly varying in-plane normal load with a circular cutout," Mechanics Research Communications, vol. 35, no. 6, pp. 61-67, 2008.

[16] E. Maiorana, C. Pellegrino, and C. Modena, "Elastic stability of plates with circular and rectangular holes subjected to axial compression and bending moment," Thin-Walled Structures, vol. 47, no. 3, pp. 241-255, 2009.

[17] C. J. Brown, A. L. Yettram, and M. Burnett, "Stability of plates with rectangular holes," Journal of Structural Engineering, vol. 113, no. 5, pp. 1111-1116, 1987.

[18] K. M. El-Sawy, A. S. Nazmy, and M. I. Martini, "Elasto-plastic buckling of perforated plates under uniaxial compression," Thin-Walled Structures, vol. 42, no. 8, pp. 1083-1101, 2004.

[19] C. D. Moen and B. W. Schafer, "Elastic buckling of thin plates with holes in compression or bending," Thin-walled Struct.vol. 47, no. 12, pp. 597-607, 2009.

[20] Y. Liu, X. Yao, and J. Su, "Analysis of elastic buckling performance of open-hole thin plates under axial compression," Ningxia Medical University, vol. 40, no. 1, pp. 45-51, 2019, In Chinese.

[21] J. Su, X. Yao, and Y. Guo, "Analysis and calculation method of elastic buckling performance of flexural open-hole thin plate," Ningxia Medical University, vol. 41, no. 1, pp. 57-62, 2020, In Chinese.

[22] T. Kawai and H. Ohtsubo, "A method of solution for the complicated buckling problems of elastic plates with combined use of Rayleigh-Ritz's procedure in the finite element method," in Proceedings of the Second Conference on Matrix Methods in Structural Mechanics, pp. 967-994, Wright-Patterson Air Force Base, Ohio, USA, August 1968.

[23] N. E. Shanmugam, V. Thevendran, and Y. H. Tan, "Design formula for axially compressed perforated plates," ThinWalled Structures, vol. 34, no. 1, pp. 1-20, 1999.

[24] American Iron and Steel Institute, AISI S100-16, "North American Specification for the Design of Cold-formed Steel Structural Members, American Iron and Steel Institute, Washington DC, USA, 2016.

[25] Australia/New Zealand Standard, AS/NZS 4600:2018, ColdFormed Steel Structures, Australia/New Zealand Standard, AS/ NZS 4600:2018, Sydney, Australia, 2018.

[26] Chinese National Standard,GB50018-2002, Technical Code for Cold-Formed Thin-Walled Steel Structures, Chinese National Standard,GB50018-2002, Beijing, China, 2002, In Chinese.

[27] ABAQUS, ABAQUS/Standard User's Manual Volumes I-III and ABAQUS CAE Manual, Dassault Systemes Simulia Corporation, Johnston, RI, USA, 2014.

[28] J.-H. Kang and A. W. Leissa, "Exact solutions for the buckling of rectangular plates having linearly varying in-plane loading on two opposite simply supported edges," International Journal of Solids and Structures, vol. 42, no. 14, pp. 4220-4238, 2005. 
[29] B. W. Schafer, Finite Strip Analysis of Thin-Walled Members, CUFSM: Cornell University-Finite strip method, New York, NY, USA, 2001.

[30] X. Yao, Y. Guo, and X. Song, "Test and analysis on axiallycompressed stud with web opening," Indian Constitution, vol. 322013, In Chinese.

[31] L. Xu, Y. Shi, and S. Yang, "Compressive strength of coldformed steel c-shape columns with slotted holes," in TwentySecond International Specialty Conference on Cold-Formed Steel Structures: Recent Research and Developments in ColdFormed Steel Design and ConstructionUniversity of MissouriRolla, Saint Louis, MI, USA, 2014.

[32] Y. Pu, M. H. R. Godley, R. G. Beale, and H. H. Lau, "Prediction of ultimate capacity of perforated lipped channels," Journal of Structural Engineering, vol. 125, no. 5, pp. 510-514, 1999.

[33] T. H. Miller and T. Pekoz, "Unstiffened strip approach for perforated wall studs," Journal of Structural Engineering, vol. 120, no. 2, pp. 410-421, 1994.

[34] Y. Guo and X. Yao, The Elastic Buckling Analysis and Effective Width Method of Plate with Holes, Nanchang Institute Of Technology, Nanchang, China, 2020. 